\title{
Survival of Neural Stem Cell Grafts in the Lesioned Spinal Cord Is Enhanced by a Combination of Treadmill Locomotor Training via Insulin-Like Growth Factor-1 Signaling
}

\author{
Dong Hoon Hwang, ${ }^{1}$ Hae Young Shin, ${ }^{1,3}$ Min Jung Kwon, ${ }^{1,3}$ Jun Young Choi,,${ }^{1,2,3}$ Buom-Yong Ryu, ${ }^{4}$ and Byung Gon Kim ${ }^{1,2,3}$ \\ ${ }^{1}$ Department of Brain Science, ${ }^{2}$ Department of Neurology, and ${ }^{3}$ Neuroscience Graduate Program, Department of Biomedical Sciences, Ajou University School of \\ Medicine, Suwon 443-721, Republic of Korea, and ${ }^{4}$ Department of Animal Science and Technology, Chung-Ang University, Ansung, 456-756, Republic of Korea
}

\begin{abstract}
Combining cell transplantation with activity-based rehabilitation is a promising therapeutic approach for spinal cord repair. The present study was designed to investigate potential interactions between the transplantation (TP) of neural stem cells (NSCs) obtained at embryonic day 14 and treadmill training (TMT) in promoting locomotor recovery and structural repair in rat contusive injury model. Combination of TMT with NSC TP at 1 week after injury synergistically improved locomotor function. We report here that combining TMT increased the survival of grafted NSCs by $>3$-fold and $>5$-fold at 3 and 9 weeks after injury, respectively. The number of surviving NSCs was significantly correlated with the extent of locomotor recovery. NSCs grafted into the injured spinal cord were under cellular stresses induced by reactive nitrogen or oxygen species, which were markedly attenuated by TMT. TMT increased the concentration of insulin-like growth factor-1 (IGF-1) in the CSF. Intrathecal infusion of neutralizing IGF-1 antibodies, but not antibodies against either BDNF or Neurotrophin-3 (NT-3), abolished the enhanced survival of NSC grafts by TMT. The combination of TP and TMT also resulted in tissue sparing, increased myelination, and restoration of serotonergic fiber innervation to the lumbar spinal cord to a larger extent than that induced by either TP or TMT alone. Therefore, we have discovered unanticipated beneficial effects of TMT in modulating the survival of grafted NSCs via IGF-1. Our study identifies a novel neurobiological basis for complementing NSC-based spinal cord repair with activity-based neurorehabilitative approaches.
\end{abstract}

Key words: insulin-like growth factor-1; neural stem cell; spinal cord injury; transplantation; treadmill

\section{Introduction}

Traumatic injuries to the spinal cord result in permanent neurological deficits, yet there is no clinically available option to promote regeneration and/or functional recovery. The past 10 years or so have witnessed several concepts of therapeutic approaches proven effective in animal models of spinal cord injury (SCI; Rossignol et al., 2007; Boulenguez and Vinay, 2009; Yoon and Tuszynski, 2012; Varma et al., 2013). One of these promising strategies is transplantation (TP) of neural stem/progenitor cells (NSCs; Kim et al., 2007; Karimi-Abdolrezaee and Eftekharpour, 2012; Ruff et al., 2012; Nakamura and Okano, 2013). Many stud-

Received Dec. 22, 2013; revised Aug. 8, 2014; accepted Aug. 12, 2014.

Author contributions: D.H.H. and B.G.K. designed research; D.H.H., H.Y.S., M.J.K., and J.Y.C. performed research; B.-Y.R. contributed unpublished reagents/analytic tools; D.H.H. and B.G.K. analyzed data; D.H.H. and B.G.K. wrote the paper.

This work was supported by a National Research Foundation of Korea grant funded by the Korean Government (Ministry of Education, Science and Technology Grant NRF-2010-359-E00014 to D.H.H.) and the Basic Science Research Program through the National Research Foundation of Korea (NRF) funded by the Ministry of Education, Science and Technology (Grant 2012R1A1A2007597 to D.H.H.). This work was also supported by an NRF grant funded by the Korean government (MSIP Grants NRF-2009-0069522, 2012R1A2A2A01013143, and 2012R1A5A2051429 to B.G.K.).

Correspondence should be addressed to Byung G. Kim, MD, PhD, Departments of Brain Science, Department of Neurology, and Neuroscience Graduate Program, Department of Biomedical Sciences, Ajou University School of Medicine, Suwon 442-721, Republic of Korea; E-mail: kimbg@ajou.ac.kr.

DOI:10.1523/JNEUROSCI.5359-13.2014

Copyright $\odot 2014$ the authors $\quad 0270-6474 / 14 / 3412788-13 \$ 15.00 / 0$ ies have reported successful NSC TP with multiple therapeutic mechanisms in preclinical animal SCI models (Ben-Hur, 2010; Sahni and Kessler, 2010; Yasuda et al., 2011; Cusimano et al., 2012). However, the extent of reported neurological improvement is frequently modest (Ruff et al., 2012). One of the hurdles that limits the efficacy of NSCs may be inadequate survival of NSC grafts (Yu et al., 2009; Li and Lepski, 2013). Previous studies have reported a rapid decline in the number of surviving NSCs grafted into the injured spinal cord (Okada et al., 2005; Cusimano et al., 2012).

Another therapeutic strategy involves locomotor circuit reactivation through physical exercise. Treadmill locomotor training (TMT) trains and activates locomotor circuits located in the lumbar spinal cord by providing sensory afferent stimulation (Edgerton et al., 2004; Roy et al., 2012). The effects of TMT have been demonstrated in rodent SCI models with variable severities and multiple training regimens (Battistuzzo et al., 2012). A recent study showed that epidural stimulation could effectively reactivate the lumbar motor circuitry to be more sensitive to sensory inputs provided by TMT (Harkema et al., 2011). This finding raises a hope that TMT with electrical and/or pharmacological neuromodulation could be an effective therapeutic option (Courtine et al., 2009; Edgerton and Roy, 2012).

There is a consensus that any single treatment strategy alone is unlikely to be sufficiently effective-that combinations of two or 
more strategies are necessary to achieve clinically meaningful functional improvement for patients with SCI. A combination of activity-based rehabilitation approaches and biological regenerative therapy would be a rational approach (Dobkin and Havton, 2004; Teng et al., 2006). Indeed, presurgery and postsurgery intensive rehabilitation is already incorporated into various cell therapy paradigms in ongoing clinical trials (Fehlings and Vawda, 2011). However, the potential therapeutic value and the neurobiological basis of combining NSC-based cell therapy and activitybased training have not been systemically investigated in animal models of SCI. The present study was designed to determine whether the combination of NSC TP and TMT can lead to enhanced locomotor function after contusive SCI at the thoracic level. Unexpectedly, we observed a dramatic enhancement of NSC graft survival in animals that were subjected to active TMT. Further investigation indicated that insulin-like growth factor-1 (IGF-1) and its downstream signaling pathways may mediate the prosurvival effect of TMT.

\section{Materials and Methods}

Animals and surgical procedures. A total of 184 adult female Sprague Dawley rats weighing 250-300 g were used. The animal numbers in separate experimental groups with different end time points are shown in detail in Table 1. Animals were subjected to a contusion injury at the ninth thoracic vertebral level using the Infinite Horizon Impactor (200 $k d y n)$. The sham operation involved only the laminectomy without contusion of the spinal cord. The bladder was expressed manually twice daily until the animals resumed self-voiding.

NSC culture and TP procedure. NSCs were obtained from transgenic GFP rats of the same strain (Sprague Dawley) to minimize the issue of immunological incompatibility between different strains or species. The spinal cords of embryos at day 14 from a GFP pregnant rat were dissected and dissociated and dissociated cells were plated in StemPro NSC SFM culture medium (Life Technologies) containing bFGF (20 ng/ml) and EGF $(20 \mathrm{ng} / \mathrm{ml})$. Primary neurospheres were expanded by passaging into tertiary neurospheres. Immediately before $\mathrm{TP}$, the tertiary neurospheres were dissociated and resuspended at a density of $1 \times 10^{5} \mathrm{cells} / \mu \mathrm{l}$. TP was performed 1 week after injury. Two injections were made at $2 \mathrm{~mm}$ rostral and caudal to the epicenter using a Hamilton syringe with a glass micropipette (tip diameter $<70 \mu \mathrm{m}$ ). Each injection consisted of $2.5 \times 10^{5}$ dissociated NSCs suspended in $2.5 \mu \mathrm{l}$ of PBS $\left(5.0 \times 10^{5}\right.$ cells in total).

TMT. All animals were pretrained for $7 \mathrm{~d}$. TMT was performed in a 4-channel Flat Treadmill System for rats (model IW-FT; IWOO Scientific). Each channel consists of a $140 \times 450 \mathrm{~mm}$ runway. TMT was initiated at $3 \mathrm{~d}$ after injury. Animals were placed in an adjustable hanging harness to partially support their body weight until they showed clear hindpaw stepping movements. Most animals regained spontaneous stepping by $7 \mathrm{~d}$ (by the time of TP) and were able to walk without the harness at a slow speed $(5 \mathrm{~m} / \mathrm{min})$ even though they could not perform weightsupported plantar stepping fully at this time. TMT was temporarily suspended after TP and restarted $3 \mathrm{~d}$ later. TMT was performed at a slow speed $(5 \mathrm{~m} / \mathrm{min})$ until animals regained weight-supported plantar stepping and the speed was gradually adjusted up to $12 \mathrm{~m} / \mathrm{min}$. TMT was performed $6 \mathrm{~d}$ per week with 3 sessions per day. Each session consisted of 20 min of training and 5 min of break. TMT continued until the animals were killed.

Behavioral assessment of locomotor recovery. Animals were randomly divided into 4 groups after receiving injury $(n=8$ per group): PBS injection (PBS), NSC TP (TP), TMT with PBS injection (TMT), and TMT with NSC TP (TP + TMT). For the Catwalk analysis, a sham group $(n=8)$ with the laminectomy only was included to obtain the baseline values for the gait parameters (total 5 groups, 40 animals for behavior study). After PBS injection or NSC TP at 1 week after injury, the animals were assigned new identification codes to ensure blind evaluation. Locomotor recovery was assessed using the Basso, Beattie, and Bresnahan (BBB) locomotor rating scale, grid walk test, and gait analysis using the Catwalk system (Noldus Information Technology). For the grid walk
Table 1. Number of animals assigned for separate experimental groups and for separate end time points in different experiments

\begin{tabular}{|c|c|c|c|c|}
\hline Group $^{a}$ & $\begin{array}{l}\text { Time point } \\
(w k)^{b}\end{array}$ & $\begin{array}{l}\text { Animal } \\
\text { no. }\end{array}$ & Experiment $^{c}$ & $\begin{array}{l}\text { Corresponding } \\
\text { figure }\end{array}$ \\
\hline \multirow[t]{4}{*}{ Sham $(n=23)$} & 9 & 8 & Behavior (Catwalk) & Fig. 1 \\
\hline & 3 & 5 & ELISA (SCS) & Fig. 5 \\
\hline & 3 & 3 & Western blot & Fig. $7 A-C$ \\
\hline & 3 & 7 & ELISA (SEC) & Fig. 11 \\
\hline \multirow[t]{3}{*}{$\operatorname{PBS}(n=18)$} & 9 & 8 & Behavior, histology & $\begin{array}{c}\text { Figs. 1, Figs. 9, } \\
\text { Figs. } 10\end{array}$ \\
\hline & 3 & 3 & Western blot & Fig. $7 A-C$ \\
\hline & 3 & 7 & ELISA (SEC) & Fig. 11 \\
\hline $\mathrm{SCl}(n=5)$ & 3 & 5 & ELISA (SCS) & Fig. 5 \\
\hline \multirow[t]{4}{*}{$\mathrm{TP}(n=32)$} & $10 \mathrm{~d}$ & 4 & Histology & Figs. 2, Figs. 4 \\
\hline & 3 & 8 & Histology & Figs. 2, Figs. 3, \\
\hline & 5 & 5 & Histology & Fig. 2 \\
\hline & 9 & 8 & Behavior, histology & Figs. 1, Figs. 2, \\
\hline
\end{tabular}

Figs. 3, Figs. 9 ,

Figs. 10

\begin{tabular}{|c|c|c|c|c|}
\hline & 3 & 7 & ELISA (SEC) & Fig. 11 \\
\hline \multirow[t]{2}{*}{ TMT $(n=15)$} & 9 & 8 & Behavior, histology & $\begin{array}{l}\text { Figs. 1, Figs. 9, } \\
\text { Figs. } 10\end{array}$ \\
\hline & 3 & 7 & ELISA (SEC) & Fig. 11 \\
\hline SCl with TMT $(n=5)$ & 3 & 5 & ELISA (SCS) & Fig. 5 \\
\hline \multirow[t]{5}{*}{$\mathrm{TP}+\mathrm{TMT}(n=32)$} & $10 d$ & 4 & Histology & Figs. 2, Figs. 4, \\
\hline & 3 & 8 & Histology & Figs. 2, Figs. 3, \\
\hline & 5 & 5 & Histology & Fig. 2 \\
\hline & 9 & 8 & Behavior, histology & $\begin{array}{l}\text { Figs. 1, Figs. 2, } \\
\text { Figs. 3, Figs. 9, } \\
\text { Figs. } 10\end{array}$ \\
\hline & 3 & 7 & ELISA (SEC) & Fig. 11 \\
\hline TP with $\lg G(n=6)$ & 5 & 6 & Histology & Figs. 6, Figs. 7D-H \\
\hline $\begin{array}{l}\text { TP with } \alpha \text { BDNF } \\
\quad(n=6)\end{array}$ & 5 & 6 & Histology & Figs. 6 \\
\hline TP with $\alpha \mathrm{NT}-3(n=6)$ & 5 & 6 & Histology & Figs. 6 \\
\hline $\begin{array}{l}\text { TP with } \alpha \mid G F-1 \\
\quad(n=6)\end{array}$ & 5 & 6 & Histology & Figs. 6, Figs. 7D-H \\
\hline TP + TMT with lgG & 5 & 6 & Histology & Figs. 6, Figs. 7D-H \\
\hline$(n=9)$ & 3 & 3 & Western blot & Fig. $7 A-C$ \\
\hline $\begin{array}{l}\text { TP + TMT with } \alpha \text { BDNF } \\
\quad(n=6)\end{array}$ & 5 & 6 & Histology & Fig. 6 \\
\hline $\begin{array}{l}\text { TP + TMT with } \alpha \text { NT-3 } \\
\quad(n=6)\end{array}$ & 5 & 6 & Histology & Fig. 6 \\
\hline TP + TMT with $\alpha$ IGF-1 & 5 & 6 & Histology & Figs. 6, Figs. 7D-H \\
\hline$(n=9)$ & 3 & 3 & Western blot & Fig. $7 A-C$ \\
\hline Total & - & 184 & - & - \\
\hline
\end{tabular}

aGroup designations: Sham, sham-operated (laminectomy only) animals; PBS, injured animals with PBS injection (control for NSC transplantation); SCI, animals with injury alone; TP, animals that received NSC TP at 1 week after injury; TMT, animals with TMT alone (PBS injection without TP); SCI with TMT, injured animals with TMT alone; TP + TMT, animals with a combination of TP + TMT. See the Materials and Methods for detailed group designations. Numbers in parentheses indicate the subtotal number of animals in each group.

${ }^{b}$ Time point refers to the duration elapsed after injury.

CELISA (SCS), ELISA experiment measuring levels of BDNF, NT-3, and IGF-1 in serum, CSF, and spinal cord parenchyma (epicenter); ELISA (SEC) ELISA experiment measuring levels of BDNF, NT-3, and GDNF in the spinal cord tissue at the epicenter and caudal regions.

test, the animals were pretrained to walk on a grid runway for $7 \mathrm{~d}$ before surgery and tested at 8 weeks after injury. The number of hindpaw placement errors per run was counted and divided by the number of total steps to produce the percentage of errors out of the total steps. The average percentage of errors was obtained from four runs for each animal. For the Catwalk, four uninterrupted crossings were included and individual footprints were identified manually. The following parameters were automatically calculated: stride length, base of support, and rotation angle. The angle of hindpaw rotation was defined as the angle (in degrees) of the hindpaw axis relative to the horizontal plane. The relative position of the forepaws and hindpaws was obtained by measuring the distance between the center pads of forepaw and hindpaw prints directly, as de- 
scribed previously (Kim et al., 2011). All animals that had undergone the behavioral assessments were killed at 9 weeks after injury for histological analysis.

Tissue processing and immunohistochemistry. For comparison of NSC graft survival, animals in the TP alone or TP + TMT group were killed at $10 \mathrm{~d}$ and 3,5 , and 9 weeks after injury $(n=4,8,5$, and 8 per group at the different time points, respectively, for a total of 50 animals for survival analysis). The animals killed at 9 weeks (TP 8, TP + TMT 8, a total of 16 animals) underwent the behavioral analysis (see Behavioral assessment of locomotor recovery, above). After cardiac perfusion with $4 \%$ paraformaldehyde, the spinal cord was dissected and postfixed, followed by cryoprotection in a graded series of sucrose solutions. Longitudinal sections (20 $\mu \mathrm{m}$ thick) of the spinal cord were cut using a cryostat (CM 1900; Leica) and thaw-mounted onto SuperFrost Plus slides (Fisher Scientific). For immunohistochemistry, sections were incubated overnight at $4^{\circ} \mathrm{C}$ with the following primary antibodies: anti-GFP (1:500, chick polyclonal; Millipore), anti-APC-CC1 (1:200, mouse monoclonal; Calbiochem), anti-GFAP (1:500, rabbit polyclonal; Millipore), anti-Tuj1 (1:400, mouse monoclonal; Millipore), anti-nestin (clone 10C2, 1:300, mouse monoclonal; Millipore), anti-nitrotyrosine (clone HM.11, 1:300, mouse monoclonal; Abcam), anti-4-hydroxynonenal (4-HNE, 1:300, rabbit polyclonal; Abcam), anti-phosphorylated-ERK (1:300, rabbit polyclonal; Cell Signaling Technology), anti-NeuN (clone A60, 1:300, mouse monoclonal; Millipore), and anti-5-HT (5-hydroxytryptamine, 1:5000, rabbit polyclonal; Immunostar). After washing, slides were incubated with appropriate secondary antibodies conjugated to the Alexa Fluor fluorescent dyes. Slides were examined using an Olympus confocal laser scanning microscope (model FV 300). For eriochrome myelin staining, the longitudinal spinal cord sections were immersed for $8 \mathrm{~min}$ in a staining solution consisting of $240 \mathrm{ml}$ of $0.2 \%$ eriochrome cyanine RC (Sigma) and 10 $\mathrm{ml}$ of $10 \% \mathrm{FeCl}_{3} \cdot 6 \mathrm{H}_{2} \mathrm{O}$ (Sigma) in $3 \% \mathrm{HCl}$. The sections were then washed with running tap water, followed by differentiation in $1 \%$ $\mathrm{NH}_{4} \mathrm{OH}$. After eriochrome cyanine staining, the sections were counterstained with an eosin solution to visualize the entire spinal cord regions and lesion cavities clearly.

Intrathecal administration of neutralizing antibodies. For administration of neutralizing antibodies, a polyethylene tube (PE-10) was inserted immediately after injury (Yaksh and Rudy, 1976; Asato et al., 2001). A small incision was made in the atlanto-occipital membrane and the tube was inserted into the cisterna magna space through the opening. The tube was advanced $4.5 \mathrm{~cm}$ caudally, aiming the catheter tip at the dorsal surface of the lesion site. Repeated bolus injections of neutralizing antibodies were performed for in vivo delivery. After each injection, the outer opening of the catheter was sealed with a custom-made plastic cap and was kept under the skin to avoid exposure to the other animals in the cage. Antibody administration was begun $3 \mathrm{~d}$ after injury when TMT was initiated and repeated every $3 \mathrm{~d}$. Neutralizing antibodies against BDNF (sheep polyclonal; Millipore, \#AB1513P), Neurotrophin-3 (NT-3, rabbit polyclonal; Millipore, \#AB1532SP), or IGF-1 (goat polyclonal; R\&D Systems, \#AF791) were administered to animals with NSC TP alone or with $\mathrm{TP}+\mathrm{TMT}$. Each injection consisted of $100 \mu \mathrm{l}$ of antibody solution at 50 $\mu \mathrm{g} / \mathrm{ml}$ in PBS (total $5 \mu \mathrm{g}$ ). For control antibodies, nonimmune goat IgGs (R\&D Systems) were administered. In an experiment to examine graft survival, a total of 9 injections were done and the animals were killed at 5 weeks after injury ( $n=6$ animals per group, total 8 groups, total 48 animals). Spinal cord sections from animals with control IgG or IGF-1 antibody administration (both the TP and TP + TMT groups) were processed for immunohistochemical analysis of the ERK phosphorylation. For the assessment of the IGF-1-dependent signaling pathway by immunoblotting, separate animals were given 5 injections and killed at 3 weeks after injury ( $n=3$ per group).

In vitro NSC death assay. The death of cultured NSCs was induced by either 3-morpholinosydnonimine (SIN-1; $400 \mu \mathrm{M}$; Enzo) or hydrogen peroxide $\left(\mathrm{H}_{2} \mathrm{O}_{2} ; 1 \mathrm{~mm}\right.$; Sigma), which produce reactive nitrogen species (RNS) or reactive oxygen species (ROS), respectively. Cultured NSCs were exposed to either SIN-1 or $\mathrm{H}_{2} \mathrm{O}_{2}$ for $48 \mathrm{~h}$ with or without IGF-1 (20 $\mathrm{ng} / \mathrm{ml})$. Three independent cultures were performed per experimental condition $(n=3)$. After the $48 \mathrm{~h}$ treatments, the percentage of apoptotic NSCs was determined using a MUSE Cell Analyzer with Annexin V and
Caspase 3/7 kits (Millipore). NSC survival was assessed using Cell Counting Kit-8 (Dojindo Laboratories) according to the manufacturer's instructions. The experiment was replicated four times with triplicate samples included in each experiment.

ELISA and Western blot analysis. The concentrations of BDNF, NT-3, and IGF-1 were measured in serum, CSF, and spinal cord tissue using ELISA kits (BDNF; Promega; NT-3; Millipore: IGF-1; R\&D Systems). The levels of the three growth factors were compared among animals with sham operation, injury alone, or injury with TMT initiated $3 \mathrm{~d}$ after injury ( $n=5$ for each group). Animals were killed 3 weeks after injury or sham operation. After anesthetization, the heart was rapidly exposed and $\sim 10 \mathrm{ml}$ of blood was withdrawn from the heart. Then, the atlantooccipital membrane was punctured using a 31-gauge syringe and $\sim 300$ $\mu \mathrm{l}$ of CSF was collected. After collection of serum and CSF, the animals were perfused with ice-cold saline for a few minutes and the portion of the thoracic spinal cord covering $\pm 5 \mathrm{~mm}$ from the lesion epicenter (the epicenter block) was rapidly dissected. The blood sample was centrifuged at $3000 \times g$ for $20 \mathrm{~min}$ to collect the supernatant serum fraction. The spinal cord tissue was homogenized in T-per lysis buffer (Thermo Scientific) containing protease inhibitor and phosphatase inhibitor cocktails (Thermo Scientific). All subsequent ELISA steps were performed according to the instruction manual. ELISA was also used to measure the concentrations of the three neurotrophic factors BDNF (Promega), NT-3 (Millipore), and GDNF (Promega). The levels of the three factors were measured in spinal cord tissue from both the epicenter block and the caudal block (the 1-cm-long tissue block extending caudally from 0.5 $\mathrm{mm}$ caudal to the epicenter). Seven animals in each group (5 groups: sham, PBS, TP, TMT, and TP + TMT) were killed at 3 weeks after injury (total 35 animals).

Western blot analysis of IGF-1 signaling proteins was performed with samples harvested 3 weeks after injury. Three animals per group were generated: (1) control (sham operated), (2) PBS (injury alone with PBS injection), (3) TP + TMT with control IgG, and (4) TP + TMT with anti-IGF-1 antibodies. The epicenter block was dissected and homogenized in the same manner as for ELISA. The blots were probed with the following primary antibodies: phosphorylated IGF-1 receptor (pIGF-1R; 1:2000, rabbit polyclonal; Cell Signaling Technology), IGF-1R (1:2000, mouse monoclonal; Millipore), and phosphorylated ERK (pERK; 1:3000, mouse monoclonal; Millipore), followed by incubation with peroxidaseconjugated secondary antibodies. Antigen-antibody reactions were visualized using a chemiluminescence kit (Thermo Scientific).

Stereological cell counting and quantitative morphometry. Stereological cell counting was performed with an Olympus model BX51 microscope attached to the MAC 6000 Motorized Stage coupled with the Stereo Investigator 8 software (MBF Bioscience). Longitudinal sections in a horizontal plane were systematically chosen at an intersection interval of $400 \mu \mathrm{m}$ (section sampling fraction $=1 / 20$ ). Optical dissectors were placed randomly and the standard stereological criteria were used. The sampling grid dimension was $300 \times 300 \mu \mathrm{m}^{2}$ with a $100 \times 100 \mu \mathrm{m}^{2}$ counting grid (area sampling fraction $=0.11$ ). Using a dissector height of $10 \mu \mathrm{m}$ in sections with an average postprocessing thickness of $18 \mu \mathrm{m}$, the height sampling fraction was $0.56(10 / 18)$. Because of the difficulty in delineating individual GFP-positive cells within grafts densely populated by surviving NSCs, the volumes of the GFP-positive grafts were obtained as another index of graft survival. To determine the volume of NSC grafts, consecutive sections stained with anti-GFP antibodies were imaged at $100 \times$ magnification and a montage image covering entire section was produced using Adobe Photoshop. The areas of discernible GFP signal at this magnification were outlined and measured using ImageJ software. The total estimated volume was calculated using Cavalieri's principle. To quantify the extent of differentiation of grafted NSCs in mature neural cell types, three consecutive sections with $400 \mu \mathrm{m}$ intersection distance were chosen. In each section, three images (total nine images per animal) containing GFP-positive grafts were obtained at $200 \times$ magnification using the FV 300 Olympus confocal microscope. The number of GFP-positive cells colocalized with a specific neural cell marker was divided by the total number of GFP cells to calculate the percentage of differentiated cells. For quantification of the percent APCCC1-positive cells, GFAP staining was done together with APC-CC1 and 
A
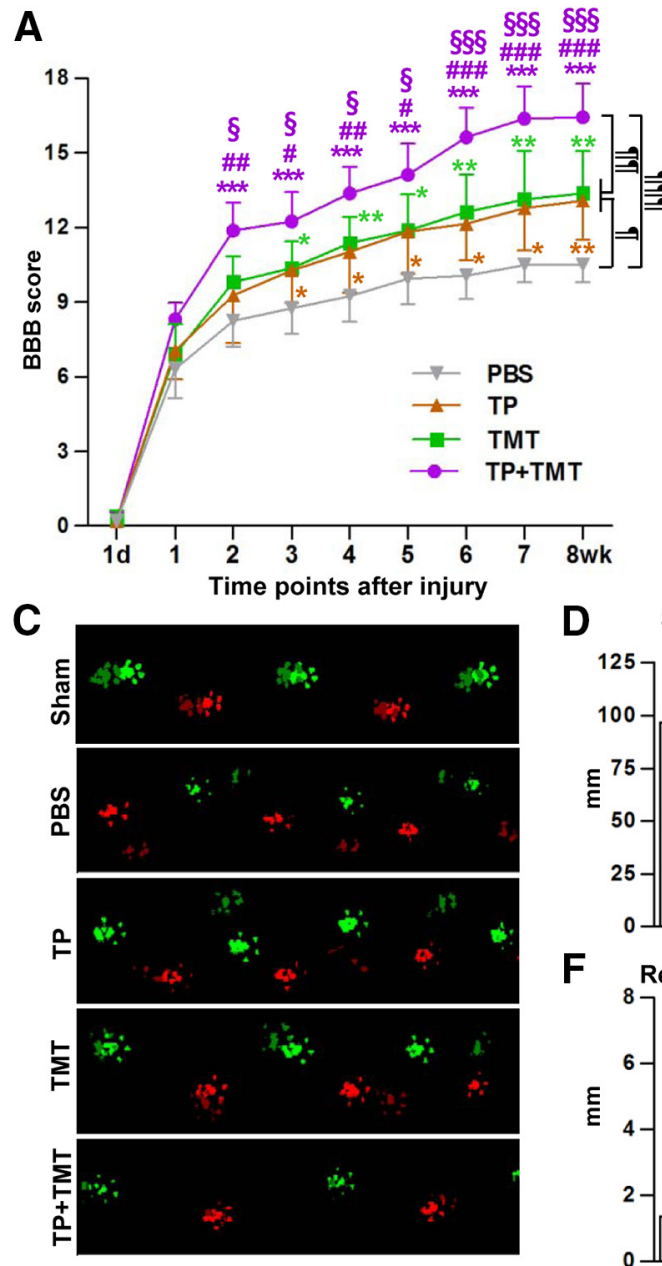

B

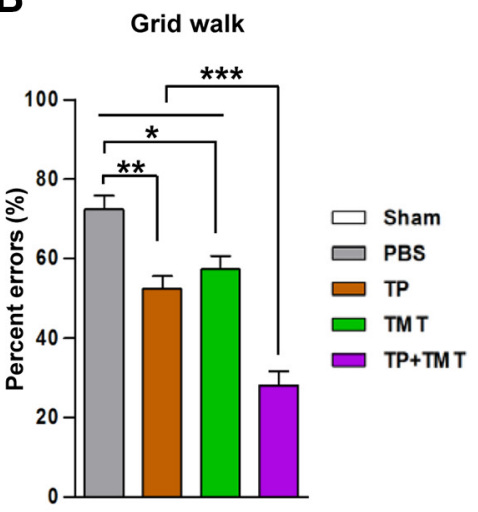

D

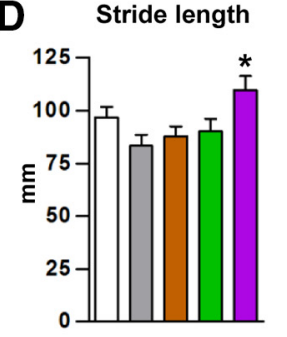

$\mathbf{F}$

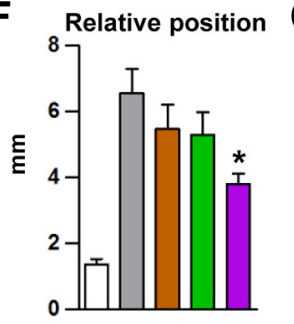

Figure 1. Combining NSC transplantation and TMT enhanced locomotor recovery. A, Recovery of BBB locomotor scores over the 8-week period after injury. Animals with the combination of NSC TP and TMT (TP + TMT) showed significantly higher locomotor

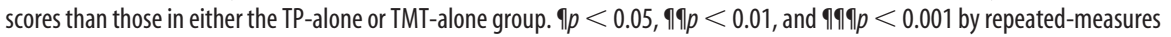
two-way ANOVA followed by Tukey's post hoc comparison between different treatment groups. ${ }^{*} p<0.05,{ }^{* *} p<0.01$, and ${ }^{* * *} p<0.001$ versus the PBS group; $\# p<0.05$, \#\#p $<0.01$, and \#\#\#p $<0.001$ versus the TP group; $\$ p<0.05$ and $\$ \S \S p<0.001$ versus TMT group by one-way ANOVA followed by Tukey's post hoc analysis at each time point. $\boldsymbol{B}$, Grid walk test performed at 8 weeks after injury. The average number of hindpaw placement errors was divided by the total number steps taken per run to obtain the percent errors. Animals in the TP + TMT group showed the highest accuracy in the grid walk. ${ }^{* *} p<0.01$ and ${ }^{* * *} p<0.001$ by one-way ANOVA followed by Tukey's post hoc analysis. C, Representative footprints measured by the Catwalk system. Footprint colors were assigned by the system software (bright green = right forepaw, bright red = left forepaw, dim green = right hindpaw, and dim red = left hindpaw). D-G, Parameters indicating the quality of locomotion were assessed at 8 weeks after SCI. The graphs show stride length (distance between the two consecutive hindpaw footprints $(\boldsymbol{D})$, base of support (width between the left and right hindpaws; $\boldsymbol{E}$ ), relative position (distance between the center pads of forepaw and hindpaw prints; $\boldsymbol{F}$ ), and rotation angle (angle of the hindpaw axis relative to the horizontal plane; $\boldsymbol{G}$ ). ${ }^{*} p<0.05$ compared with the PBS group by one-way ANOVA followed by Tukey's post hoc analysis. $n=8$ animals per group (including the sham group in the (atwalk test) in all behavioral tests.

GFP (triple staining) to exclude astrocytes with GFAP immunoreactivity. Less than $5 \%$ of the cells positive for both APC-CC1 and GFP were GFAP positive, and these cells were not included for the quantification of GFPpositive NSCs differentiated into oligodendrocytes. The same method was applied to the quantification of NSCs colocalized with nitrotyrosine, 4-HNE, and pERK signals. 3D reconstruction of lesion cavities was done using the Neurolucida system (MBF Bioscience). The software generated the $3 \mathrm{D}$ images and calculated the volumes of spared tissue and lesion cavities. To quantify the percentage of myelinated area, longitudinal sections stained with eriochrome cyanine were imaged at a $200 \times$ magnification. The eriochrome-stained areas above a predetermined threshold were quantified as a percentage of total spinal cord areas using ImageJ. To quantify the density of 5-HT axons in the caudal lumbar motor regions, two longitudinal sections $400 \mu \mathrm{m}$ apart containing the ventral regions were chosen from each animal. The regions of interest caudal to the
E Base of support

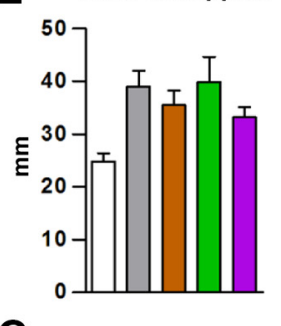

G

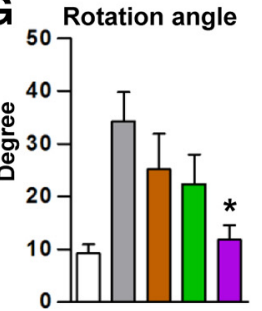

epicenter (10 $\mathrm{mm}$ on average) were imaged at $200 \times$ magnification and the number of pixels occupied by the 5 -HT fibers was quantified using the ImageJ (see Fig. 10E). This value was then divided by the number of 5-HT fiber pixels from the rostral regions of interest to generate percentage 5-HT axonal fiber density. The fiber densities from the two images were averaged for each animal. The spinal cord sections for the 5-HT staining were doubly stained with NeuN antibody to analyze the 5-HT axon terminals around the ventral motor neurons qualitatively.

Statistical methods. Statistical analysis was performed with GraphPad Prism and SPSS software. Unpaired Student's $t$ test or one-way ANOVA was used for comparison of group means. Repeated-measures two-way ANOVAs were used to compare differences in BBB scores matched at different time points. Pearson correlation analysis was performed to determine linear association of two variables. Error bars in all graphs represent mean \pm SEM.

\section{Results}

Combination of NSC TP and TMT

enhances locomotor recovery

We evaluated how the combination of NSC grafts (transplanted at $7 \mathrm{~d}$ after injury) and TMT affected behavioral outcomes after SCI. TP or TMT alone significantly improved overground $\mathrm{BBB}$ locomotor scores compared with animals with PBS injection, but the combination of the two strategies $(\mathrm{TP}+\mathrm{TMT})$ resulted in superior improvement compared with the TPalone or TMT-alone groups (Fig. 1A). The effect of combined TP and TMT had already become evident at 2 weeks, and the treatment effects of individual interventions (TP or TMT) started to be significant at 3 weeks after injury. Repeated-measures twoway ANOVA revealed a significant interaction between treatment conditions and the time points after SCI $(p<0.001)$. Tukey's post hoc analysis revealed a statistically significant difference in the mean BBB scores of the TP + TMT and PBS groups $(p<0.001)$. Moreover, the improvement by the combined strategy was also significantly greater than that induced by TP or TMT alone $(p<0.01)$. In the grid walk test, animals with injury alone (PBS group) showed paw placement errors in $>70 \%$ of total steps (Fig. $1 B$ ). TP and TMT alone both significantly reduced the percentage of stepping errors. The percent errors decreased to $<25 \%$ with the combination of TP and TMT, and the differences between the combined treatment and the TP or TMT alone group were statistically significant $(p<0.001)$. In the Catwalk test, the mean stride length was shortened after injury (Fig. 1C,D). TP or TMT alone did not significantly affect the stride length. Only the combination of the two resulted in a significant increase (Fig. 1D). The base of support tended to increase after injury, but was not affected by any intervention (Fig. 1E). In uninjured animals, the forepaw and hindpaw footprints almost overlapped with each other (Fig. 1C). 


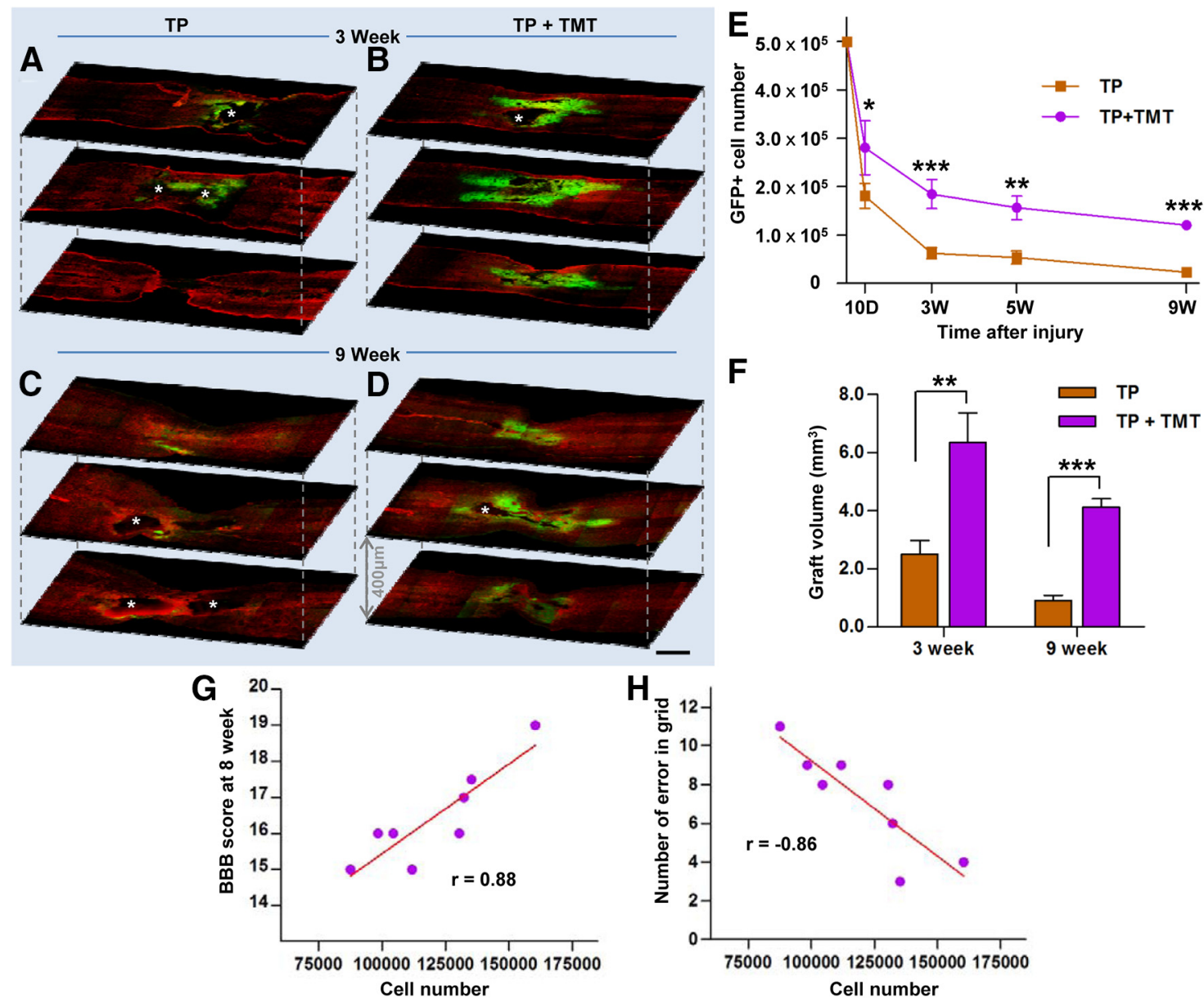

Figure 2. Survival of transplanted NSCs in the injured spinal cord. $\boldsymbol{A}-\boldsymbol{D}$, Representative confocal microscopy images of injured spinal cord sections from the TP-alone $(\boldsymbol{A}, \boldsymbol{C})$ and TP + TMT groups $(\boldsymbol{B}, \boldsymbol{D})$ at $3(\boldsymbol{A}, \boldsymbol{B})$ or 9 weeks $(\boldsymbol{C}, \boldsymbol{D})$ after injury (2 or 8 weeks after TP, respectively). Spinal cord sections were immunostained with anti-GFP (green) and anti-glial fibrillary acidic protein (GFAP; red) antibodies to visualize the distribution of the grafted NSCs in relation to the lesions. Asterisks indicate lesion cavities. Scale bar, $1 \mathrm{~mm}$. E, Stereological counts of grafted cells at each time point. $n=$ $4,8,5$, and 8 animals in each group at $10 \mathrm{~d}$ and 3,5 , and 9 weeks after injury ( $3 \mathrm{~d}$ and 2,4 , and 8 weeks, respectively, after TP). ${ }^{*} p<0.05$, ${ }^{* *} p<0.01$, and ${ }^{* * *} p<0.001$ by one-way ANOVA followed by Tukey's post hoc analysis. $F$, Quantification of NSC graft volume at 3 and 9 weeks after injury ( 2 and 8 weeks after TP). ${ }^{* *} p<0.01$ and ${ }^{* * *} p<0.001$ by Student's $t$ test. $n=8$ animals per group. $\boldsymbol{G}, \boldsymbol{H}$, Number of surviving NSCs and the BBB locomotor scores $(\boldsymbol{G})$ or the number of hindpaw placement errors in the grid walk $(\boldsymbol{H})$ at the last trials ( 8 weeks after injury) were plotted for the 8 animals in the TP + TMT group. Each circle represents each animal. Correlation coefficient $(r)$ was calculated using Pearson correlation analysis. The two variables were significantly correlated in both analyses $(p<0.01)$.

After injury, uncoordinated forepaw and hindpaw placement occurred, and the footprints of the forepaw and hindpaw were frequently mismatched, resulting in an increase in their relative position. The TP and TMT alone groups showed slight improvements, but the group with the combination of the two individual interventions showed a significant decrease in the relative position (Fig. $1 F$ ). After SCI, the angle of hindpaw rotation relative to the body axis increases, indicating an outward, abducted position of the hindpaws during stepping. Only the $\mathrm{TP}+\mathrm{TMT}$ group showed a significant reduction in the rotation angle (Fig. 1G). These results indicated that NSC TP and TMT acted synergistically to produce behavioral outcomes superior to the individual interventions.

\section{TMT enhances the survival of NSC grafts}

To determine the potential mechanisms in the synergistic interaction of NSC TP and TMT, we first compared the survival of NSC grafts between animals with TP alone and TP combined with TMT at 9 weeks after injury (all animals underwent the behavioral analysis). In the TP-alone group, few NSC grafts were visible at a low magnification, whereas appreciable GFP-positive grafts were frequently observed in TP + TMT group at the same time point (Fig. 2C,D). Only 4.6\% (22,752 \pm 4120$)$ of the transplanted NSCs survived in the TP-alone group. The survival rate in the TP + TMT group was $>5$ times as high $(120,065 \pm 8396$, $24.0 \%$ ) as that in the former group. The majority of grafted NSCs surrounded the lesion cavities at the epicenter, but they also migrated along the rostrocaudal axis to populate the host tissue distant from the epicenter (mean maximal rostrocaudal distance of the grafts, $13.0 \pm 0.5 \mathrm{~mm}$; Fig. $2 D$ ). The graft survival was also examined at earlier time points. The beneficial effect of TMT on grafted cell survival was significant as early as $3 \mathrm{~d}$ after TP $(10 \mathrm{~d}$ after injury; Fig. $2 E$ ), but the difference became more prominent at 2 weeks after TP ( 3 weeks after injury; Fig. $2 A, B, E$ ). At this time point, most surviving NSC grafts were observed along the cavity walls in animals with TP alone. In the TP + TMT group, substantial areas at the epicenter were occupied by the grafts and an apparent migration to the rostrocaudal direction was observed (Fig. 2B). The mean number of surviving NSCs in TP + TMT group $(184,660 \pm 30,094,36.9 \%)$ was 3 times as large as that in TP-alone group $(62,025 \pm 11,577,12,4 \%)$ at 3 weeks after injury. The loss of grafted NSCs persisted up to 9-week time point, 

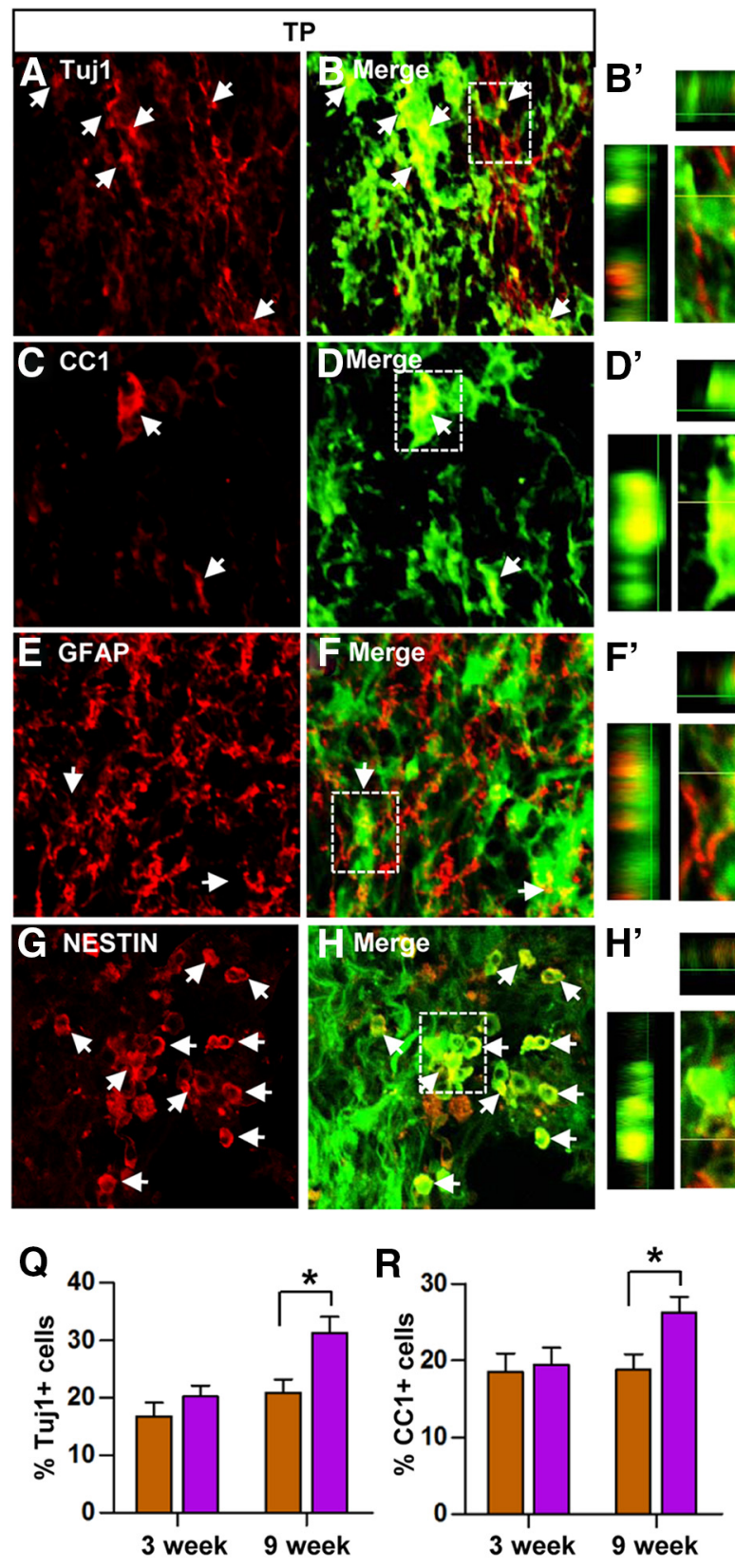
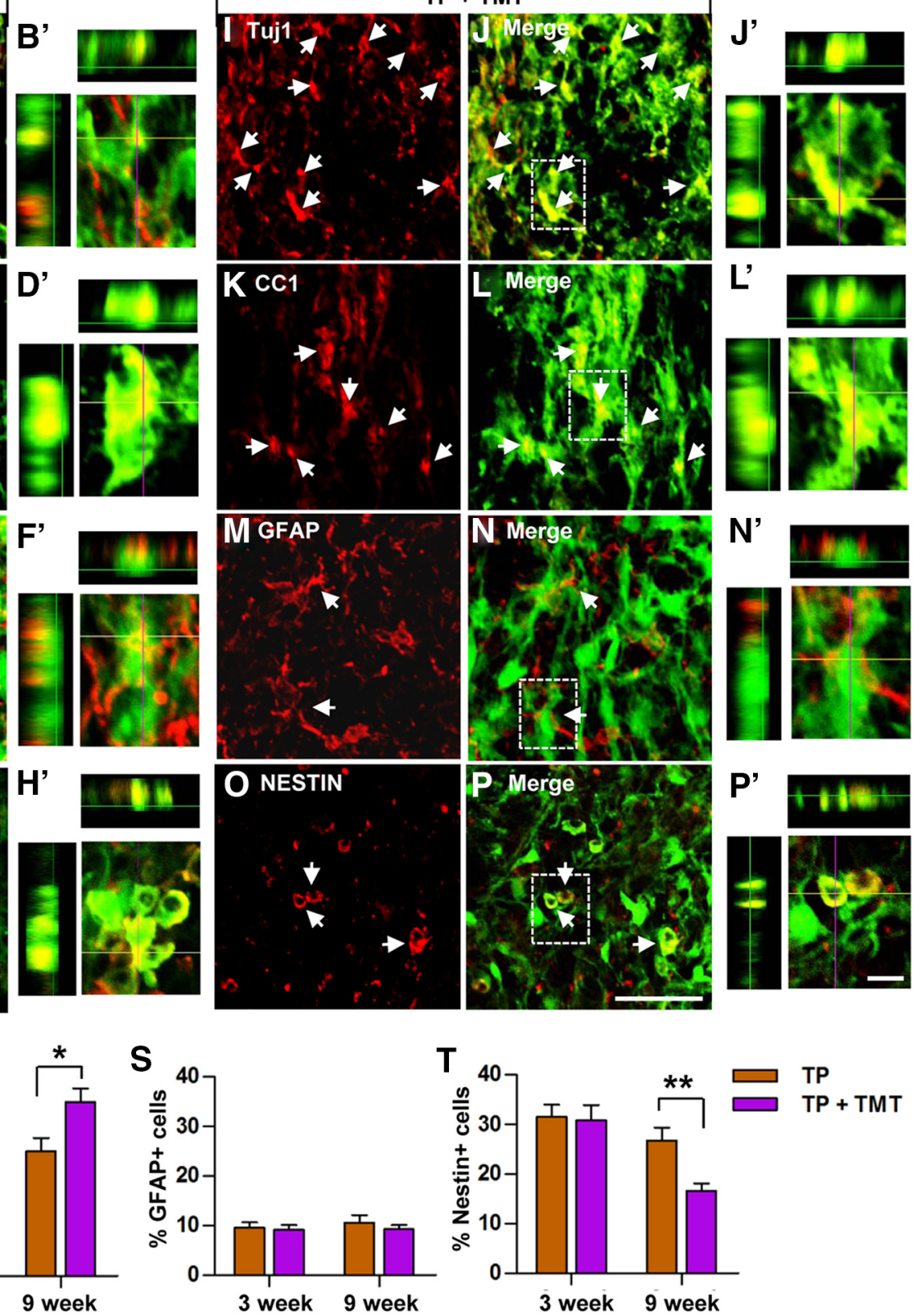

Figure 3. Phenotypic differentiation of NSCs after transplantation into the injured spinal cord. $\boldsymbol{A}-\boldsymbol{P}$, Representative images of grafted NSCs in the spinal cord from animals in the TP-alone ( $\boldsymbol{A}-\boldsymbol{H})$ or TP + TMT $(I-P)$ group that were killed at either 3 or 9 weeks after injury. Neural cell phenotypes were determined by immunoreactivities (red) for the neuronal marker Tuj $1(\boldsymbol{A}, \boldsymbol{I})$, the mature oligodendrocyte marker APC-CC1 $(\boldsymbol{C}, \boldsymbol{K})$, the astrocytic marker GFAP $(\boldsymbol{E}, \boldsymbol{M})$, and the undifferentiated NSC marker nestin $(\boldsymbol{G}, \mathbf{0})$. GFP-positive NSCs (green) colocalizing with neural cell markers are shown in yellow and are indicated by arrows $(\boldsymbol{B}, \mathbf{D}, \boldsymbol{F}, \boldsymbol{H}, \mathbf{J}, \mathbf{L}, \mathbf{N}, \boldsymbol{P})$. Scale bar, $50 \mu \mathrm{m} .\left(\boldsymbol{B}^{\prime}, \boldsymbol{D}^{\prime}, \boldsymbol{F}^{\prime}, \boldsymbol{H}^{\prime}, \boldsymbol{J}^{\prime}, \boldsymbol{L}^{\prime}, \boldsymbol{N}^{\prime}, \boldsymbol{P}^{\prime}\right)$ Higher magnification and orthographic projection images of the boxed areas in $\boldsymbol{B}, \boldsymbol{D}, \boldsymbol{F}, \boldsymbol{H}, \boldsymbol{J}, \boldsymbol{L}, \boldsymbol{N}$, and $\boldsymbol{P}$, respectively. Scale bar, $10 \mu \mathrm{m}$. $\mathbf{Q}-\boldsymbol{T}$, Quantification of the percentage of NSCs that differentiated into neurons (Tuj1; $\mathbf{Q})$, oligodendrocytes (CC1; $\boldsymbol{R})$, or astrocytes (GFAP; $\boldsymbol{S}$ ) or did not show into any specific neural cell type (nestin; $T$ ) at 3 and 9 weeks after injury. ${ }^{*} p<0.05$ and ${ }^{* *} p<0.01$ by Student's $t$ test. $n=8$ per group.

whereas the rate of NSC loss declined after the 3-week time point in both groups (Fig. 2E). As an additional measure of survival, the volume of GFP-positive NSC grafts recognizable at a low magnification was also calculated. TMT increased the graft volume by 2.5 - and 4.5 -fold at 3 and 9 weeks after injury, respectively, compared with that in animals without TMT (Fig. $2 F$ ). There were very few, if any, proliferating NSCs (doubly positive for GFP and the proliferation marker Ki67) in animals with or without TMT (data not shown), excluding the possibility that TMT enhances proliferation rather than survival of NSCs. To determine whether enhanced survival of grafted NSCs is related to the behavioral improvement, we performed a correlation analysis between the number of surviving NSCs and behavioral measures in the TP + TMT group animals (Fig. 2G,H). The BBB score measured at the 8-week time point was nicely correlated with the number of surviving NSCs $(r=0.86, p<0.01)$ and the number of errors in the grid walk was inversely correlated with the cell survival $(r=$ $-0.86, p<0.01)$.

Grafted NSCs differentiated into the three mature neural cell types or remained undifferentiated as nestin-positive NSCs (Fig. $3 A-P)$. The extent of differentiation was not significantly different between animals with or without TMT at 3 weeks. However, the proportions of GFP-positive cell colocalizing with Tuj1 (a neuron marker) or CC1 (an oligodendrocyte marker), but not 

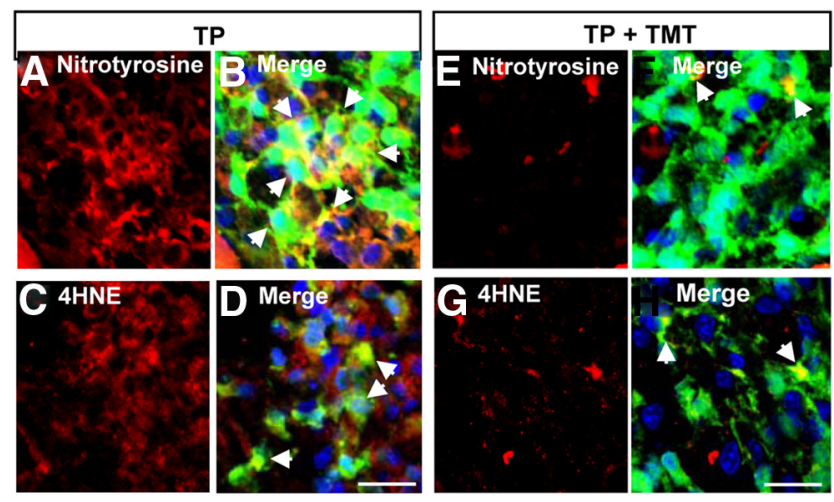

I

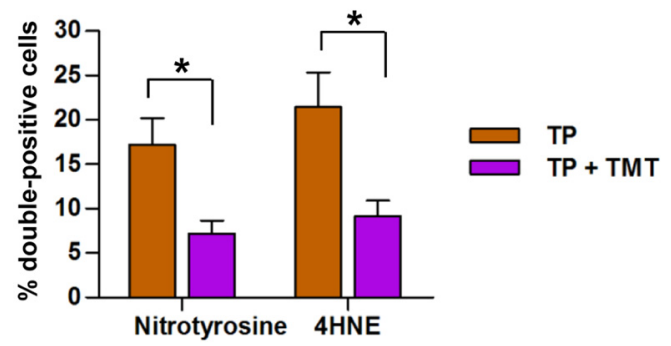

Figure 4. TMT attenuates cellular stresses induced by reactive nitrogen species or reactive oxygen species in grafted NSCs. $\boldsymbol{A}-\boldsymbol{H}$, Representative images of spinal cord sections doublestained with anti-GFP (green) and the marker of RNS anti-nitrotyrosine (red; $A, B, E, F)$ or the marker of ROS anti-4-HNE (red; $\boldsymbol{C}, \boldsymbol{D}, \boldsymbol{G}, \boldsymbol{H}$ ) at $3 \mathrm{~d}$ after transplantation ( $10 \mathrm{~d}$ after spinal cord injury). All the images were taken at the epicenter region. The nuclei were visualized using DAPI (blue; $\boldsymbol{B}, \boldsymbol{D}, \boldsymbol{F}, \boldsymbol{H}$ ). Arrows indicate transplanted cells colocalizing with the RNS or ROS markers. The number of nitrotyrosine- and 4-HNE-positive cells were significantly decreased in the TP + TMT group $(\boldsymbol{E}-\boldsymbol{H})$ compared with the TP-alone group $(\boldsymbol{A}-\boldsymbol{D})$. Scale bar, $20 \mu \mathrm{m}$. I, Quantification of the percentage of transplanted NSCs colocalizing with anti-nitrotyrosine or anti-4HNE immunoreactivity. ${ }^{*} p<0.05$ by Student's $t$ test. $n=4$ per group.

with GFAP (an astrocyte marker), were significantly higher in animals with TMT than those without TMT at 9 weeks after injury (Fig. 3Q-S). Consistent with this finding, the percentage of undifferentiated NSCs (nestin-positive) at 9 weeks after injury was significantly reduced by TMT (Fig. $3 T$ ).

\section{TMT attenuates RNS- and ROS-induced cellular stresses in grafted NSCs}

Increased ROS and RNS may be the principal factors contributing to secondary tissue damage after CNS injuries (Liu et al., 2000; Kubota et al., 2012). Recent studies have shown that ROS and RNS are also involved in the regulation of NSC death (Cheng et al., 2001; Yu et al., 2009; Sakata et al., 2012; Tseng et al., 2014). Therefore, we investigated whether grafted NSCs at the epicenter region in the spinal cord sections obtained $3 \mathrm{~d}$ after TP $(10 \mathrm{~d}$ after injurym when the loss of grafted NSC is rapidly progressing, see Fig. 2E) were under ROS- and RNS-induced cellular stresses by using antibodies against nitrotyrosine as a marker of RNS and against 4-HNE, a reactive aldehyde generated by peroxides, as a marker of ROS. GFP-positive NSCs often colocalized with either nitrotyrosine $(17.2 \pm 3.0 \%)$ or 4 -HNE $(21.5 \pm 3.9 \%)$ immunoreactivity (Fig. $4 A-D$ ). In animals subjected to TMT, grafted NSCs were rarely positive for either nitrotyrosine or 4-HNE immunoreactivity (Fig. $4 E-H$ ). The differences between the TPalone and the TP + TMT groups in the percentage of NSCs under RNS or ROS stress were statistically significant (Fig. 4I), suggesting that TMT may enhance the survival of grafted NSCs in part by attenuating RNS- and ROS-induced cellular stresses.
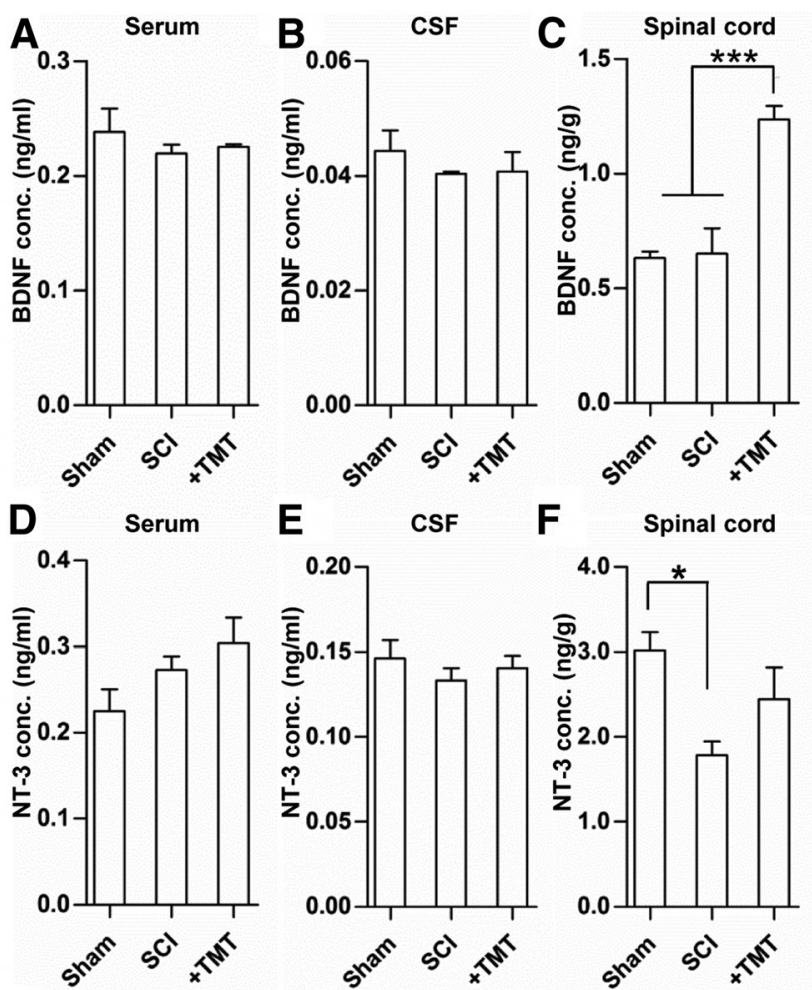

$\mathrm{E}$

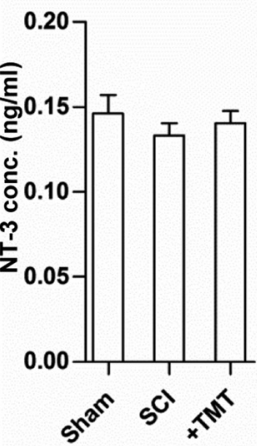

$\mathbf{F}$
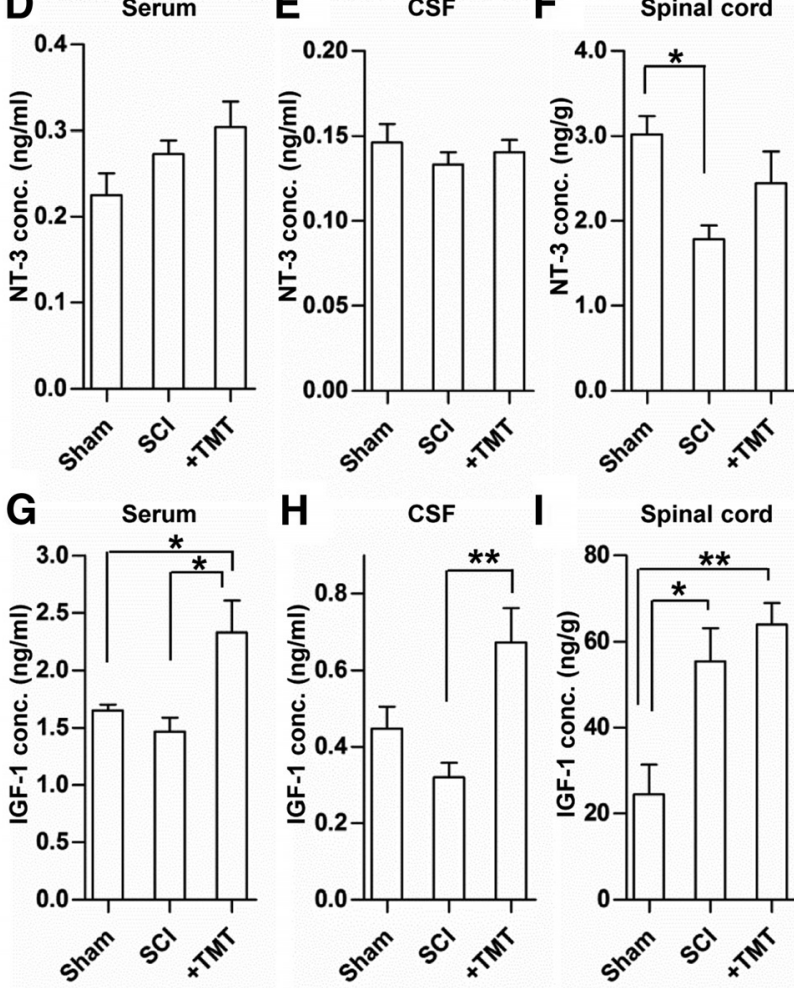

Figure 5. Measurements of growth factors after spinal cord injury and TMT. ELISA analysis of the concentration of BDNF $(\boldsymbol{A}-\boldsymbol{C}), \mathrm{NT}-3(\boldsymbol{D}-\boldsymbol{F})$, and IGF-1 $(\boldsymbol{G}-\boldsymbol{I})$ in sham-operated animals (CTL), injured animals (SCI), and injured animals subjected to TMT (+TMT). TMT was initiated at $3 \mathrm{~d}$ after injury and maintained thereafter. All animals were killed at 3 weeks after injury and the serum, CSF, and spinal cord tissue at the epicenter region were obtained from each animal. Concentrations of all the three growth factors were measured in the serum $(A, D, G), C S F(B, E$, $\boldsymbol{H})$, and spinal cord tissue $(\boldsymbol{C}, \boldsymbol{F}, \boldsymbol{I})$ from 5 animals in each group. ${ }^{*} p<0.05,{ }^{* *} p<0.01$, and ${ }^{* * *} p<0.001$ by one-way ANOVA followed by Tukey's post hoc analysis.

Intrathecal delivery of IGF-1-neutralizing antibodies abolishes TMT-induced prosurvival effects on transplanted NSCs

We hypothesized that TMT may enhance the survival of grafted NSCs by producing certain growth factors. As for a candidate growth factor, we selected BDNF and NT-3 because these two neurotrophins have been traditionally linked to the beneficial effects of various exercise regimens (Gómez-Pinilla et al., 2001; Ying et al., 2005; Boyce et al., 2007; Côté et al., 2011). We also chose IGF-1 because previous studies have reported that exercise increases peripheral production of IGF-1 that can be delivered to the CNS, mediating neuroplasticity (Fernandez and TorresAlemán, 2012). We measured the concentration of the three 

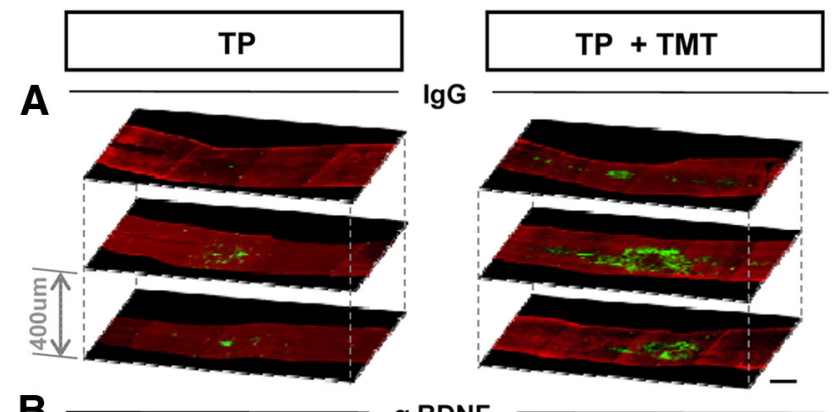

B

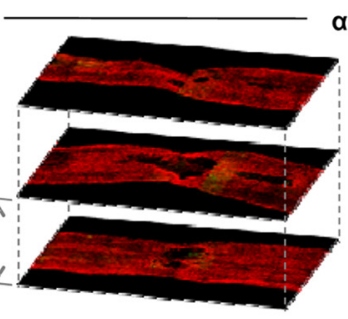

$\alpha$ BDNF

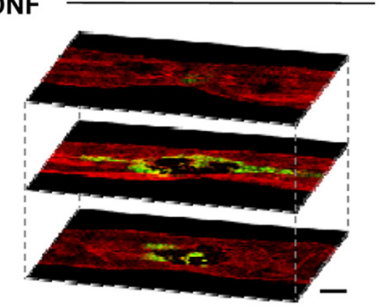

C

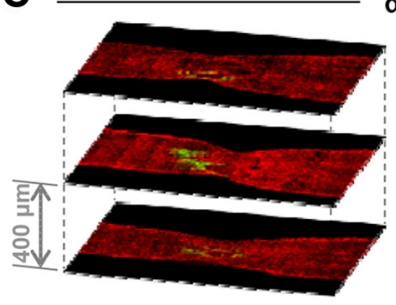

a NT-3
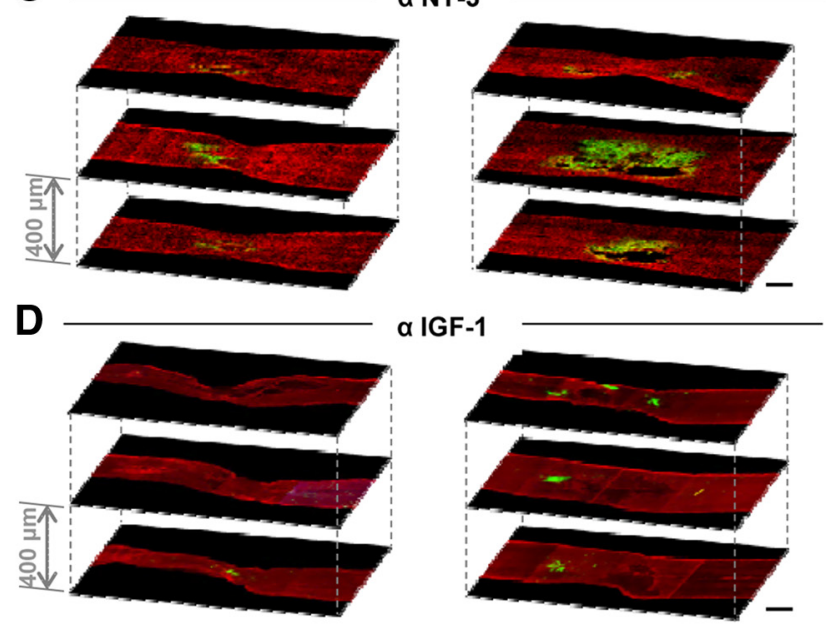

a IGF-1
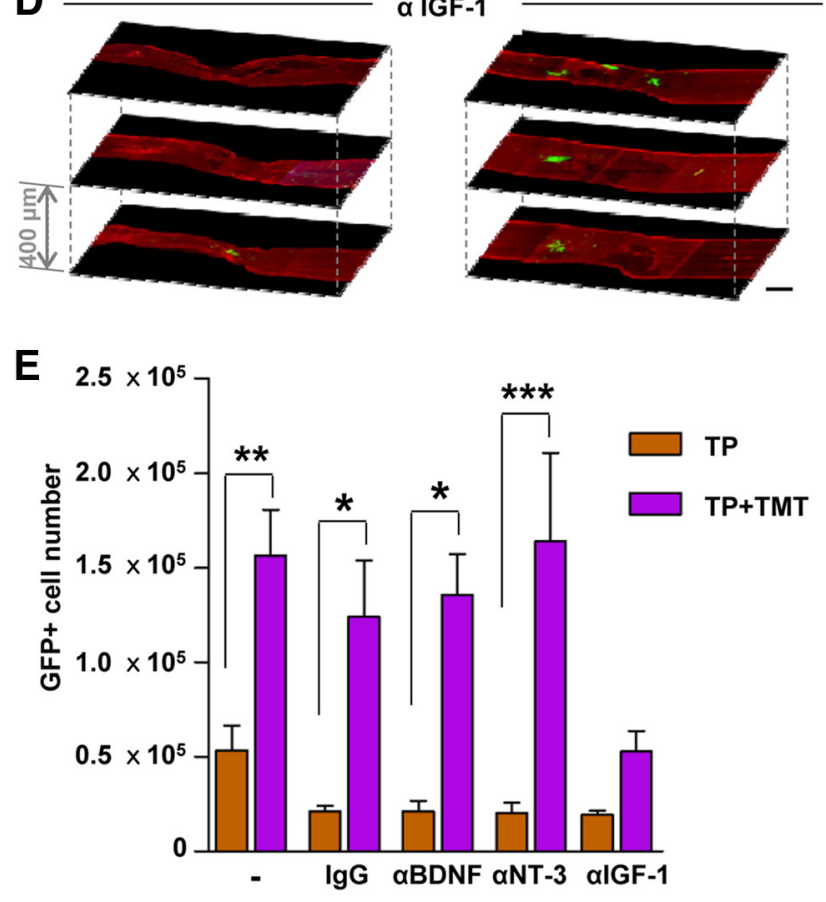

Figure 6. Neutralization of IGF-1 abrogated the effects of TMT on NSC graft survival. $\boldsymbol{A}-\boldsymbol{D}$, Representative confocal microscopy images of injured spinal cord sections at 5 weeks after injury (4 weeks after transplantation). Animals received intrathecal control $\lg G(\boldsymbol{A})$ or neutralizing antibodies against BDNF $(\boldsymbol{B})$, NT-3 $(\boldsymbol{C})$, or IGF-1 (D). Serial spinal cord sections (intersection thickness $400 \mu \mathrm{m}$ ) were immunostained with anti-GFP (green) and anti-GFAP (red) antibodies to visualize the distribution of the grafted NSCs in relation to the lesion. In the left column are representative images of animals in TP-alone group. In the right column are TP + TMT images. Enhanced survival of NSCs by TMT was evident in animals with control $\lg G(\boldsymbol{A})$ and antibodies against BDNF $(\boldsymbol{B})$ and NT-3 $(\boldsymbol{C}$. Neutralization of IGF-1 abrogated the TMT effects of graft survival (D). $\boldsymbol{E}$, Stereological counts of surviving GFP-positive NSCs. The data for the first two bars (without any antibodies) were borrowed from Figure 2 (survival at 5 weeks) and are shown growth factors in the serum, in the CSF obtained from the cisterna magna, and in the thoracic spinal cord tissue from the injury epicenter at 3 weeks after SCI. The BDNF (Fig. $5 A, B$ ) or NT-3 level (Fig. $5 D, E$ ) was not significantly altered in the serum or CSF in injured animals with or without TMT. In the spinal cord tissue, TMT significantly elevated the BDNF level compared with uninjured animals or injured animals without TMT (Fig. $5 C)$. In contrast, NT-3 level was significantly reduced in injured animals compared with the uninjured, and TMT tended to restore the NT-3 level (Fig. 5F). IGF-1 concentration in the serum was not changed by injury, but the level was markedly increased by TMT (Fig. 5G). In the CSF, the IGF-1 concentration was slightly reduced by injury, but significantly increased by TMT (Fig. 5H). SCI itself significantly increased the IGF-1 level in the spinal cord tissue and TMT did not significantly affect the IGF-1 level compared with that in injured animals without TMT (Fig. $5 I)$. The CSF IGF-1 levels were highly correlated with those of the serum $(r=0.92, p<0.001)$, but not with those in the spinal cord tissue $(r=0.47, p>0.05$; data not shown), suggesting that the CSF IGF-1 level may be influenced by peripheral IGF-1 concentration.

To determine which growth factor plays an essential role in mediating the effects of TMT on the survival of grafted NSCs, neutralizing antibodies against BDNF, NT-3, or IGF-1 were delivered intrathecally to the animals with NSC TP alone or combined with TMT and the survival rate of grafted NSCs was compared at 5 weeks after injury ( 4 weeks after TP). As expected, GFP-positive NSC grafts were readily observed in animals subjected to TMT with control IgG antibodies (Fig. 6A,E). Likewise, the survival of grafted NSCs was increased by $>5$-fold by TMT regardless of whether BDNF or NT-3 antibody was administered (Fig. 6B, C,E). In contrast, intrathecal IGF-1 administration substantially reduced the prosurvival effects of TMT (Fig. 6D,E), suggesting that the TMT effect on the survival of grafted NSCs may be largely mediated by IGF-1. The number of surviving NSCs in the TP-alone group tended to be slightly reduced by control IgG, probably due to nonspecific Ig effects or catheter related physical influence. However, basal survival rate of NSCs (in animals without TMT) was not significantly altered by any neutralizing antibodies compared with control IgG (Fig. 6E). In the spinal cord, phosphorylation of IGF-1R was greatly increased by TP + TMT compared with sham control or injured animals with only PBS injection, and this effect was almost completely abrogated by intrathecal delivery of IGF-1-neutralizing antibodies (Fig. $7 A, B$ ). A similar pattern was observed for the phosphorylation of ERK (Fig. $7 A, C$ ), a major downstream kinase mediating the IGF-1-dependent prosurvival signaling. Activated ERK signaling was also visualized by immunofluorescence staining. In animals with TP alone, very few GFP-positive NSCs colocalized with phosphorylated ERK (Fig. 7D,F). When TMT was combined with TP, $>30 \%$ of the grafted NSCs showed activation of ERK signaling (Fig. $7 E, H$ ). Intrathecal administration of IGF-1neutralizing antibodies markedly reduced the percentage of NSCs with phosphorylated ERK (Fig. 7G,H).

Prosurvival effects of IGF-1 on cultured NSCs were evaluated. NSC death was induced by SIN-1 or $\mathrm{H}_{2} \mathrm{O}_{2}$ to incur RNS or ROS,

$\leftarrow$

as reference. The TMT effect was suppressed only by the IGF-1 antibodies. No antibodies affected NSC graft survival in animals without TMT. ${ }^{*} p<0.05,{ }^{* *} p<0.01$, and ${ }^{* * *} p<0.001$ by Student's $t$ test between the TP-alone and TP + TMT groups with the treatment of the designated antibodies. $n=6$ animals per group ( $n=5$ for groups without any antibody). 

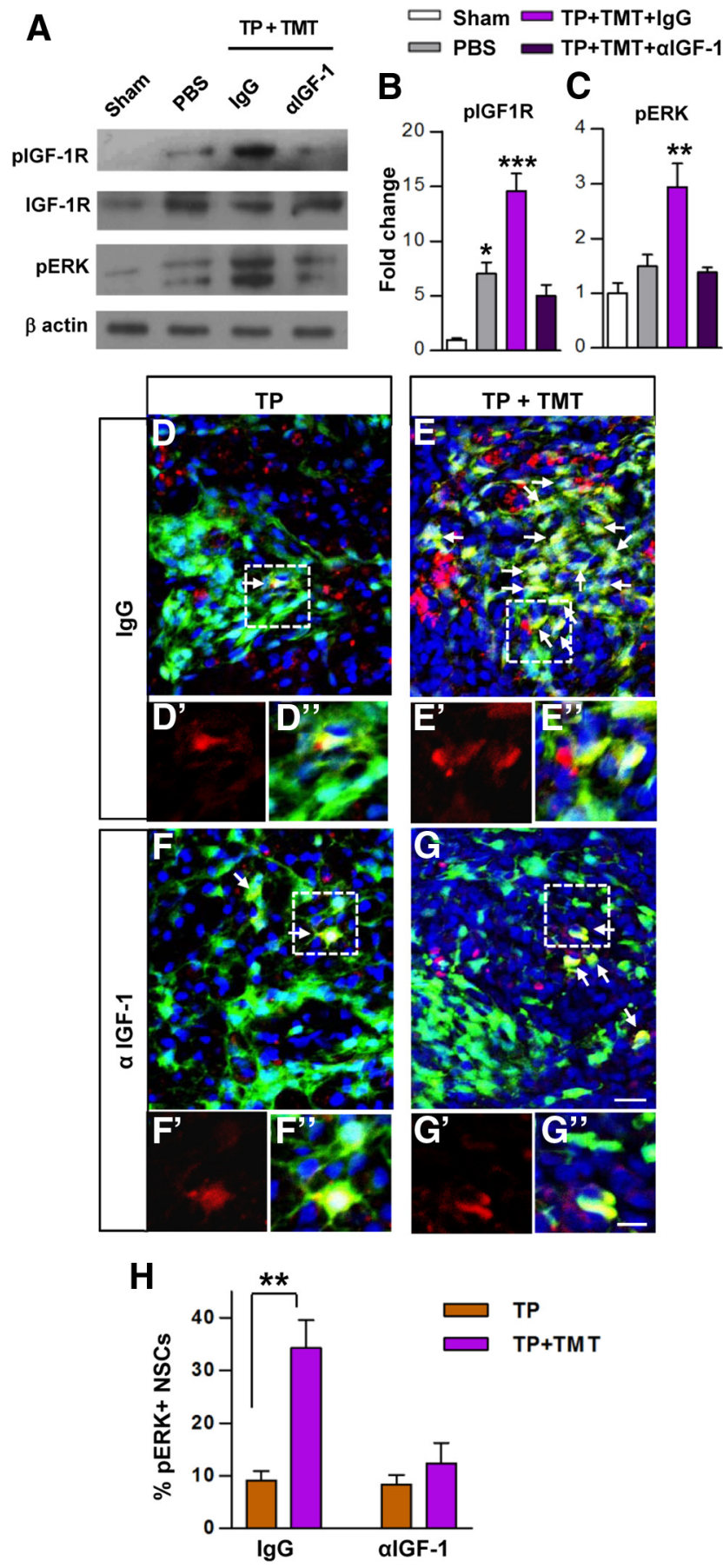

Figure 7. Analysis of the phosphorylation of IGF-1 receptor and ERK. A, Western blot analysis of IGF-1 receptor (IGF-1R) and ERK phosphorylation status using the epicenter spinal cord tissue harvested at 3 weeks after injury. The phosphorylated IGF-1R level was greatly increased in the combined intervention group (TP + TMT, with control nonimmune IgG infusion) compared with sham-operated control (CTL) or injury-alone (with PBS injection only) groups, and infusion of IGF-1-neutralizing antibodies completely abolished the increase. None of the experimental conditions affected the expression of total IGF-1R protein. The phospho-ERK level was also substantially increased in the TP + TMT group and the increase was blocked by the IGF-1neutralizing antibodies. $\boldsymbol{B}, \boldsymbol{C}$, Quantification of phosphorylated IGF-1R $(\boldsymbol{B})$ and ERK $(\boldsymbol{C})$ levels. ${ }^{*} p<0.05,{ }^{* *} p<0.01$, and ${ }^{* *} p<0.001$ compared with control by one-way ANOVA followed by Tukey's post hoc analysis. $n=3$ animals per group. $\boldsymbol{D}-\boldsymbol{F}$, Representative images of spinal cord sections double-stained for GFP (green) and phosphorylated ERK (red) in the NSC TP-alone $(\boldsymbol{D}, \boldsymbol{F})$ and TP + TMT $(\boldsymbol{E}, \boldsymbol{G})$ groups administered with either control $\lg \boldsymbol{(} \boldsymbol{D}, \boldsymbol{E})$ or neutralizing antibodies against IGF- $1(\boldsymbol{F}, \boldsymbol{G})$ at 5 weeks after injury (4 weeks after TP). Arrows indicate cells colocalizing with both markers. Boxed regions were magnified with only red channel (phosphoERK signal; $\left.\boldsymbol{D}^{\prime}-\boldsymbol{G}^{\prime}\right)$ or with all channels $\left(\boldsymbol{D}^{\prime \prime}-\boldsymbol{G}^{\prime \prime}\right)$. DAPI was used for counterstaining of nuclei. respectively, for $48 \mathrm{~h}$. Treatment of NSCs with SIN-1 or $\mathrm{H}_{2} \mathrm{O}_{2}$ increased the proportion of apoptotic NSCs-positive for annexin $\mathrm{V}$ or caspase 3/7 (Fig. 8A, $B, D, E$ ). The addition of IGF-1 (20 $\mathrm{ng} / \mathrm{ml}$ ) to cultured NSCs effectively reduced the proportion of apoptotic NSCs in response to SIN-1-mediated toxicity (Fig. $8 A, B)$. IGF-1 slightly attenuated $\mathrm{H}_{2} \mathrm{O}_{2}$-mediated toxicity, but this effect was not statistically significant (Fig. $8 D, E$ ). In a cell survival assay, both SIN-1 and $\mathrm{H}_{2} \mathrm{O}_{2}$ significantly reduced the number of viable NSCs by $>50 \%$, but IGF- 1 treatment almost completely prevented this RNS- and ROS-mediated loss of NSCs (Fig. 8C,F).

\section{Combination of NSC TP and TMT promoted the structural repair}

Next, we investigated the influence of the combined intervention on the structural repair of the host spinal cord tissue. Volumes of the lesion cavity and the spared spinal cord tissue were measured in 3D reconstruction images (Fig. 9A,B). NSC grafting alone tended to decrease the cavity volumes, although the difference was not statistically significant (Fig. 9B,C). However, TMT alone did not provide any obvious beneficial effects on cavity formation. Only when the two strategies were combined were the cavity volumes significantly decreased compared with the injury-alone group (Fig. 9C). TP or TMT alone resulted in the preservation of spinal cord tissue to some degree, but the combination of the two increased the volume of spared tissue to an even greater degree (Fig. $9 D$ ). Either TP or TMT alone increased the myelinated areas, but the combination of TP and TMT resulted in even larger myelinated areas than that in the TP-alone or TMT-alone groups (Fig. 9E).

We also evaluated the extent of serotonergic (5-HT) axon innervation to the ventral motor areas in the lumbar segments (Fig. 10A-D). Contusive injury to the thoracic segments resulted in a dramatic decrease in the density of 5-HT axons in the lumbar spinal cord (Fig. 10A). TMT alone significantly restored the 5-HT axon density, whereas NSC TP to the lesion site only slightly affected the extent of 5-HT immunoreactivity (Fig. 10 B, C,F). In TMT-alone group, neurons in the ventral horn were more frequently contacted by $5-\mathrm{HT}$ axon terminals than those in PBSalone or TP-alone group (Fig. 10A'-C $C^{\prime}$ ). The combination of TP and TMT led to the largest increase in 5-HT fiber density, reaching a level $>3$-fold that in the injury alone group (Fig. 10D,F), and the neurons in the ventral horn were also frequently surrounded by the 5 -HT axon terminals (Fig. 10D').

We also investigated whether the combination treatment resulted in enhanced production of neurotrophic factors (BDNF, NT-3, and GDNF) that can contribute to the structural repair of the host spinal cord (Fig. 11). The BDNF level at the epicenter region was significantly increased by NSC TP (Fig. 11A) at 3 weeks after injury. TMT also tended to increase the BDNF level. The combined intervention achieved the highest concentration, but the difference between the combination group and TP alone was not evident. At the caudal lumbar spinal cord region, TP or TMT alone tended to increase the BDNF level, but there was no significant synergism between TP and TMT (Fig. 11D). The NT-3 level was substantially reduced after injury at both the epicenter and caudal regions (Fig. 11B,E). Either TP or TMT alone tended to slightly increase the NT-3 levels, but the effects of individual

Scale bars, 20 and $10 \mu \mathrm{m}$ for magnified images. $\boldsymbol{H}$, Quantification of the percentage of NSCS positive for phosphorylated ERK. ${ }^{* *} p<0.01$ by Student's $t$ test between the TP-alone and the TP + TMT groups. $n=6$ per group. 
A Annexin V

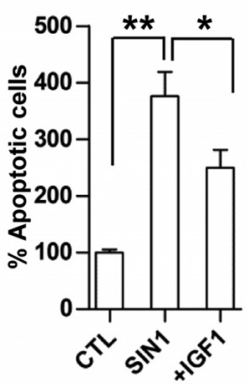

B Caspase 3/7

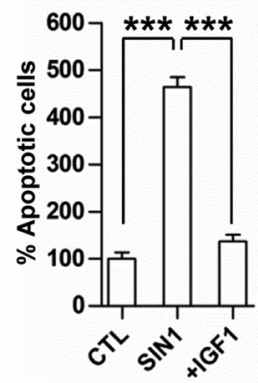

E

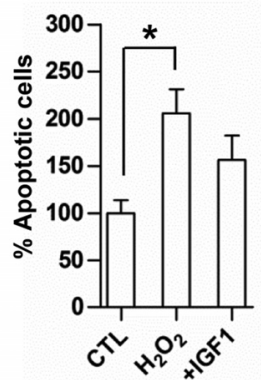

C Viability assay

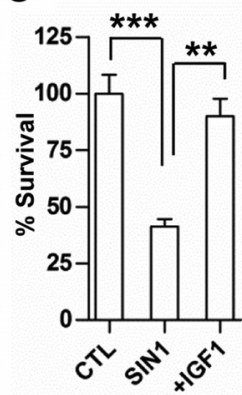

F Viability assay

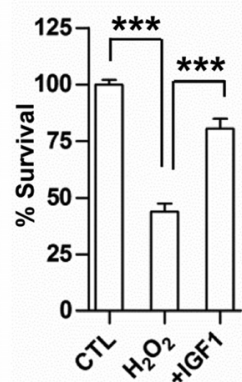

Figure 8. Antiapoptotic and prosurvival effects of IGF-1 on cultured NSCS. NSCS were exposed to either $\mathrm{SIN}-1(400 \mu \mathrm{m} ; \boldsymbol{A}-\mathrm{C})$ or $\mathrm{H}_{2} \mathrm{O}_{2}(1 \mathrm{~mm} ; \boldsymbol{D}-\boldsymbol{F})$ to produce RNS or ROS, respectively, for $48 \mathrm{~h}$ with (+IGF-1) or without IGF-1 $(20 \mathrm{ng} / \mathrm{ml})$. The extent of apoptosis was determined based on the reactivity to annexin $V(\boldsymbol{A}, \boldsymbol{D})$ or caspase $3 / 7(\boldsymbol{B}, \boldsymbol{E})$. The percentage of apoptotic cells in the treatment groups were expressed as the percent value compared with that of control (CTL) condition (without treatment with SIN-1 or $\mathrm{H}_{2} \mathrm{O}_{2}$ ). $n=3$ independent cultures per group for the apoptosis assay. The viability of NSCs was measured using Cell Counting Kit-8 $(\boldsymbol{C}, \boldsymbol{F}) . n=$ 4 independent cultures per group for the cell survival assay. ${ }^{*} p<0.05,{ }^{* *} p<0.01$, and ${ }^{* * *} p<0.001$ by one-way ANOVA followed by Tukey's post hoc analysis.

interventions were not significant. TP + TMT significantly increased the NT-3 level compared with the injury-alone (PBS) group at the epicenter. The NT-3 level at the caudal spinal cord was highest again in TP + TMT group. The GDNF level was also decreased in the injured spinal cord at both the epicenter and caudal regions, and TMT alone substantially increased the GDNF levels (Fig. 11C,F). TP + TMT further increased the GDNF level even higher than the control levels at both regions.

\section{Discussion}

The most intriguing finding in this study was marked enhancement by TMT of NSC graft survival in the injured spinal cord. Grafted NSCs were under RNS- or ROS-mediated cellular stresses that were relieved by TMT. Intrathecal administration of neutralizing antibodies against IGF-1, but not BDNF or NT-3, significantly reduced the effects of TMT on the survival of NSC grafts. The combination of NSC TP and TMT greatly reduced the volume of lesion cavities, increased the volume of spared spinal cord tissue and the extent of myelinated areas, and enhanced 5-HT axon innervation in the ventral motor regions of the lumbar spinal cord, all to a larger extent than either TP or TMT alone. We postulate that improved survival of NSC grafts by combined TMT may contribute significantly to the enhanced structural repair and the synergistic improvement in functional recovery by the combined intervention observed in this study.

Previous studies have reported poor survival of grafted NSCs in lesioned spinal cord (Okada et al., 2005; Karimi-Abdolrezaee et al., 2006; Cusimano et al., 2012). However, it has not been fully

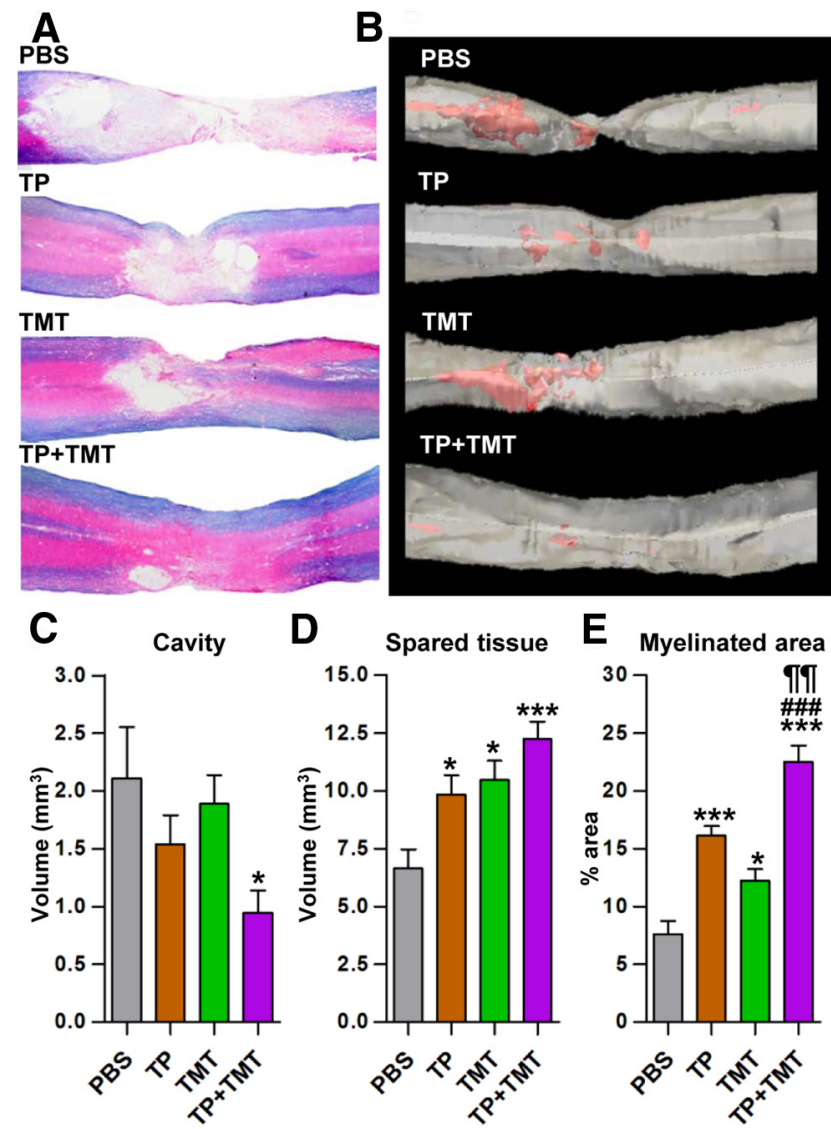

Figure 9. Structural repair of injured spinal cord at the lesion level by combined NSC trans plantation and TMT. $\boldsymbol{A}$, Representative images of the lesion epicenter region stained with eriochrome cyanine $R C$ to visualize the spared white matter and eosin counter-staining in the injury-alone (PBS), TP-alone, TMT-alone, and TP + TMT groups. Animals were killed 8 weeks after injury. $\boldsymbol{B}, 3 \mathrm{D}$ reconstruction images from the same animals as in $\boldsymbol{A}$. Red color represents cystic cavity. $\boldsymbol{C}-\boldsymbol{E}$, Comparison of the lesion cavity volume $(\boldsymbol{C})$, spared tissue volume $(\boldsymbol{D})$, and percentage of myelinated area $(\boldsymbol{E})$ within the spared spinal cord tissue. ${ }^{*} p<0.05$ and ${ }^{*} p<$ 0.001 compared with the injury-alone group (PBS), $19 p<0.01$ compared with the TP-alone group, and \#\#\# $<0.001$ compared with the TMT-alone group, by one-way ANOVA followed by Tukey's post hoc analysis. $n=8$ animals per group for all analyses.

understood how grafted stem cells undergo death in host tissue and what environmental factors play critical roles in the demise of NSCs. A previous study reported that peroxynitrite-derived RNS induced NSC death in vitro and in the injured spinal cord in vivo (Yu et al., 2009). Markers of RNS- and ROS-induced stresses were elevated acutely after SCI and lingered up to several days (Bao et al., 2005; Xiong and Hall, 2009) when NSCs were transplanted in this study. In addition, it is highly likely that TP procedure itself may lead to the second bout of RNS or ROS production, escalating the risk of grafted NSCs being exposed to RNS or ROS. Indeed, a significant portion of grafted NSCs colocalized with RNS or ROS markers, indicating that subacutely (7 d after injury) transplanted NSCs are under cellular stresses mediated by either RNS or ROS. Numerous studies have shown that exercise or training can mitigate RNS- or ROS-related stresses or damages through mechanisms involving bolstering antioxidant system, trophic factor expression, modulation of signaling pathways, and so forth (Radak et al., 2008a; Radak et al., 2008b; Stranahan et al., 2010; Al-Jarrah et al., 2013; Camiletti-Moirón et al., 2013; Speck et al., 2014). Although specific mechanisms remain to be elucidated in this study, our results showed attenuation of 

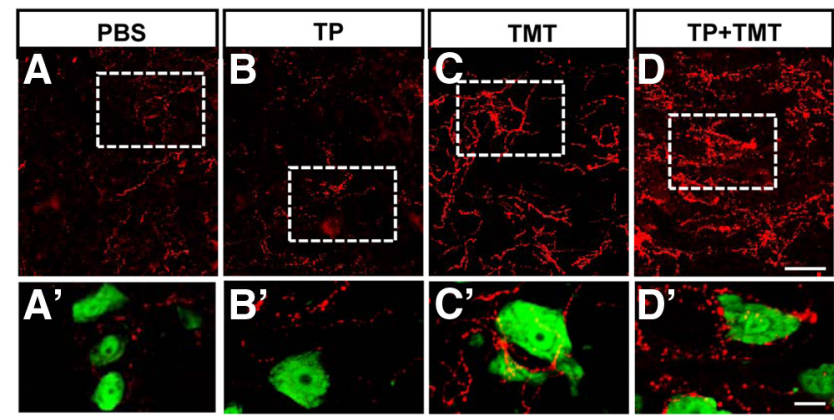

E

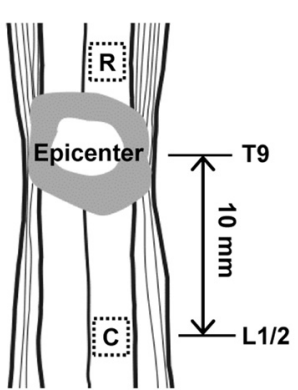

$\mathbf{F}$

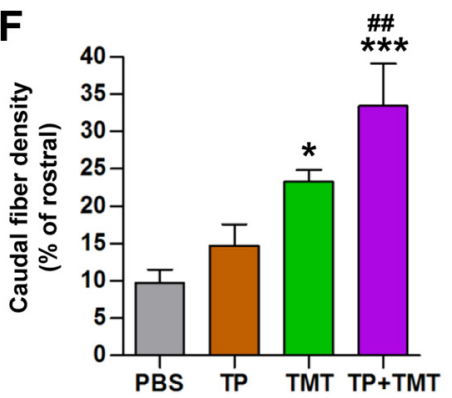

Figure 10. Density of serotonergic (5-HT) axons in the caudal lumbar motor region. $\boldsymbol{A}-\boldsymbol{D}$, Serotonergic (5-HT) axons in the lumbar ventral motor areas were visualized by immunofluorescence staining in longitudinal sections of the injured spinal cord at 9 weeks after injury. After $\mathrm{SCl}$, the density of 5-HT axons in the region caudal to the lesion was markedly reduced $(\boldsymbol{A})$. Animals in the TP + TMT group showed the most robust increase in 5-HT axon density (D). $\boldsymbol{A}^{\prime}-\boldsymbol{D}^{\prime}$, Magnified images of the boxed regions in $\boldsymbol{A}-\boldsymbol{D}$. Neurons were visualized by NeuN staining (green). Spinal motor neurons were frequently contacted by 5 -HT axon terminals in TMT-alone and TP + TMT groups. Scale bars, 50 and $20 \mu \mathrm{m}$ for magnified images. $\boldsymbol{E}$, Illustration of the location of regions of interest (boxed) in the longitudinal plane. The center of the caudal motor regions was, on average, $10 \mathrm{~mm}$ apart from the epicenter. Rostral regions of interest were used to control for differences in the intensity of immunoreactive signals between individual sections. $\boldsymbol{F}$, Quantification of the caudal 5-HT axon density as a percentage of that in the rostral region. ${ }^{*} p<0.05$ and ${ }^{* * *} p<0.01$ compared with PBS group; \#\# $<0.01$ compared with the TP-alone group by one-way ANOVA followed by Tukey's post hoc analysis. $n=8$ animals per group.

RNS- and ROS-induced cellular stresses by TMT, which may in part contribute to the enhanced survival of NSC grafts.

Our experiment using intrathecal administration of neutralization antibodies pointed to IGF-1 in the CSF as a potential growth factor mediating the prosurvival effects of TMT. IGF-1 is protective to stem cell death in various cytotoxic conditions (Enoki et al., 2010; Lunn et al., 2010; Li et al., 2012). We also demonstrated directly that IGF-1 treatment increased the survival of NSCs under either RNS or ROS stresses in vitro (Fig. 8). Previous studies have shown that exercise increases the serum IGF-1 level and stimulates the uptake of IGF-1 to the CSF compartment (Carro et al., 2000; Llorens-Martin et al., 2010). Therefore, it is highly likely that the IGF-1 level in the CSF compartment was influenced directly by the serum level in our experiments. The levels of BDNF and NT-3 in the serum and CSF compartments were not changed, but the BDNF level in the spinal cord tissue was significantly elevated by TMT (Fig. 5C). However, enhanced graft survival by TMT was not affected by intrathecal administration of BDNF-neutralizing antibodies. There is no definitive answer as to why neutralization of the BDNF increase in the spinal cord parenchyma could not suppress survival of grafted NSCs. One speculation is that growth factors in the parenchyma may have limited access to the NSCs existing as cellular aggregates after being transplanted. For example, BDNF produced in the host spinal cord by TMT would be trapped or hindered by nu-

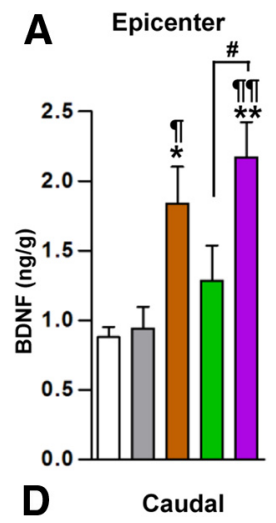

B Epicenter

C Epicenter
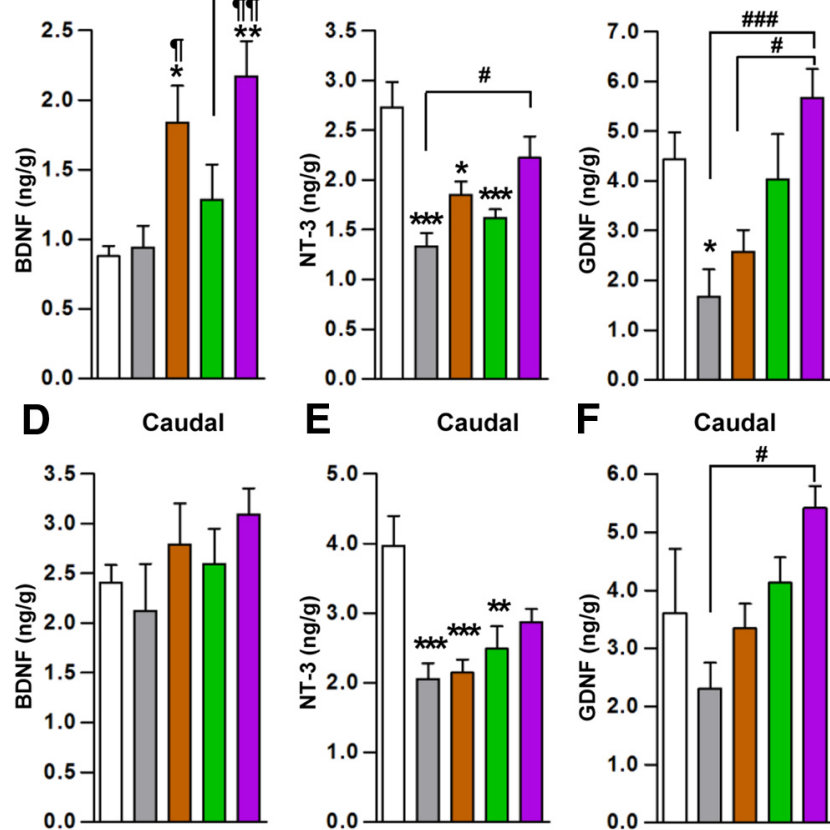

E

Caudal
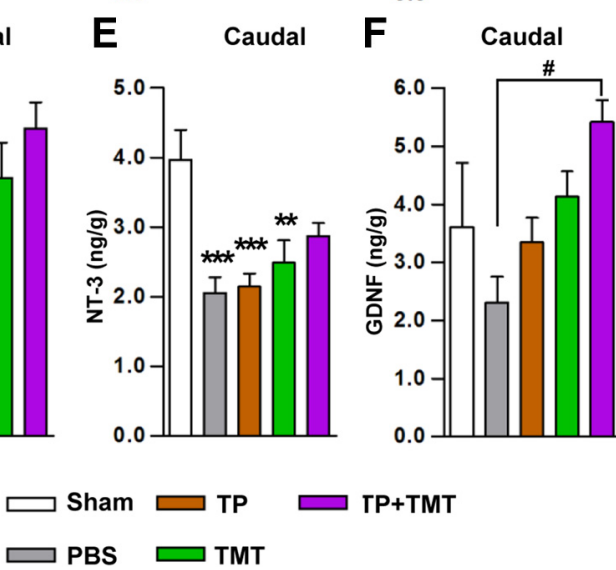

\section{TP+TMT}

Figure 11. Measurement of neurotrophic factors in the spinal cord tissue. $\boldsymbol{A}-\boldsymbol{F}$, The concentration of $\operatorname{BDNF}(\boldsymbol{A}, \boldsymbol{D}), \mathrm{NT}-3(\boldsymbol{B}, \boldsymbol{E})$, and $\operatorname{GDNF}(\boldsymbol{C}, \boldsymbol{F})$ in the spinal cord tissue was measured by ELISA. One-centimeter-long spinal cord tissue blocks were collected from both the epicenter $(\boldsymbol{A}-\boldsymbol{C})$ and the caudal $(\boldsymbol{D}-\boldsymbol{F})$ regions 3 weeks after injury, and were processed separately for ELISA analysis. ${ }^{*} p<0.05,{ }^{* *} p<0.01$, and ${ }^{* *} p<0.001$ compared with the sham-operated

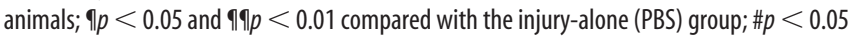
and \#\#\# $<0.001$ compared with the indicated groups by one-way ANOVA followed by Tukey's post hoc analysis. $n=7$ animals per group.

merous interacting molecules in the extracellular matrix, leading only to the increase in a local (vicinity of the producing cells) concentration but not diffusing to the NSCs within the graft. In comparison, elevation of a growth factor concentration in the CSF compartment might have more potent influence on the grafted NSCs via a delivery through a humoral access. In traumatic brain injury, various growth factors and neurotrophins in the CSF can be distributed or conveyed to the injury site via an endocrine-like mechanism, providing potent proregenerative and neuroprotective supports (Johanson et al., 2011). This notion might explain why the high concentration of IGF-1 in the spinal cord parenchyma after injury (Fig. 5I) was not effective in maintaining survival of NSC grafts. Alternatively, BDNF may not be an important survival factor for NSCs, as has been reported previously (Ahmed et al., 1995). Further studies will be required to delineate specific requirements for survival of NSC grafts.

Our results demonstrated that the combination of TP and TMT led to synergistic improvement in locomotor recovery. Because behavioral recovery was correlated with the number of surviving NSCs (Fig. 2G,H), it is reasonable to consider that the enhanced graft survival may be a crucial factor in the functional synergism between NSC TP and TMT. The higher number of surviving NSCs may make a significant contribution to the structural repair of injured spinal cord tissue. It is known that NSCs secrete a high amount of neurotrophic factors that provide protective or proregenerative effects to the host spinal cord tissue ( $\mathrm{Lu}$ 
et al., 2003). Indeed, we found that the combination of TP and TMT led to the highest concentration of neurotrophic factors such as BDNF, NT-3, and, especially, GDNF at the epicenter region. Alternatively, the presence of more NSCs could exert more powerful modulatory effects on immune cells, leading to a greater amelioration of the secondary degenerative process (Cusimano et al., 2012). Enhanced survival should afford to provide a larger number of new neurons and oligodendrocytes derived from the NSCs to the lesioned spinal cord. Enhanced long-term differentiation of NSCs into neuronal or oligodendroglial cells by TMT (Fig. 3) could amplify the TMT effect on the availability of new neurons or oligodendrocytes. Newly added oligodendrocytes would participate in the remyelination process, leading to a substantial increase in myelinated areas by TP + TMT (Fig. 9E). Increases in the availability of new neurons in the spinal cord may provide more opportunities to make alternative axonal connections across the lesion site using propriospinal connections (Bareyre et al., 2004). A recent study reported that stem cell graft survival was enhanced dramatically by a mixture of various growth factors and a calpain inhibitor and that surviving NSCs were able to mount long-range axon growth (Lu et al., 2012). These results suggest an interesting possibility that improving graft survival may not result merely in providing a larger number of cells, but may also lead to an activation of intrinsic neuronal programs such as axonal growth and formation of synaptic connections. The ERK activation in NSCs induced by TMT in this study (Fig. 7E) could be an example of this because ERK has been shown previously to activate, not only survival, but also neuronal programs that contribute to axonal sprouting and plasticity (Impey et al., 1999; Oh et al., 2009). Therefore, enhancing NSC graft survival by TMT may provide newly generated neurons that have higher intrinsic capacity of integration with host neural connections.

A major mechanism by which TMT contributes to locomotor recovery is thought to be by promoting plasticity of the neural pathways involved in the central pattern generators (Edgerton et al., 2004). Therefore, it is possible that TMT-induced changes in functional properties in the locomotor network (Petruska et al., 2007; Flynn et al., 2013) also contributed to the potentiation of NSC-mediated locomotor recovery by TMT independently of graft survival. We also found that TMT alone significantly increased the extent of 5-HT innervation in the lumbar spinal cord region (Fig. 10). The higher axon density in TMT alone group might reflect enhanced neuroprotection or an increase in sprouting of supraspinal axons. The increase in the axon density, however, was very slight in TP-alone compared with TMT-alone group, whereas the extent of tissue preservation (volumes of cavity and spared tissue) was higher in the TP-alone group or at least comparable between the two groups (Fig. 9). Considering this discrepancy, it is more likely that axonal sprouting mechanism was enacted by TMT in the caudal lumbar region. Indeed, previous studies have shown that TMT can enhance sprouting of supraspinal axons (Goldshmit et al., 2008; Oh et al., 2009). Combining NSC and TP resulted in the highest density of 5-HT fibers in the caudal lumbar region. This increase was accompanied by a prominent increase of the GDNF level in the caudal region by the combined intervention. Because GDNF plays a significant role in axonal regeneration and sprouting (Blesch and Tuszynski, 2009), the increase in GDNF level in the caudal lumbar region may partly explain the largest restoration of 5-HT innervations in the combination group.

\section{References}

Ahmed S, Reynolds BA, Weiss S (1995) BDNF enhances the differentiation but not the survival of CNS stem cell-derived neuronal precursors. J Neurosci 15:5765-5778. Medline

Al-Jarrah M, Obaidat H, Bataineh Z, Walton L, Al-Khateeb A (2013) Endurance exercise training protects against the upregulation of nitric oxide in the striatum of MPTP/probenecid mouse model of Parkinson's disease. NeuroRehabilitation 32:141-147. CrossRef Medline

Asato F, Butler M, Blomberg H, Gordh T (2001) Distribution of intrathecal catheter positions in rat. Acta Anaesthesiol Scand 45:608-611. CrossRef Medline

Bao F, Dekaban GA, Weaver LC (2005) Anti-CD11d antibody treatment reduces free radical formation and cell death in the injured spinal cord of rats. J Neurochem 94:1361-1373. CrossRef Medline

Bareyre FM, Kerschensteiner M, Raineteau O, Mettenleiter TC, Weinmann O, Schwab ME (2004) The injured spinal cord spontaneously forms a new intraspinal circuit in adult rats. Nat Neurosci 7:269-277. CrossRef Medline

Battistuzzo CR, Callister RJ, Callister R, Galea MP (2012) A systematic review of exercise training to promote locomotor recovery in animal models of spinal cord injury. J Neurotrauma 29:1600-1613. CrossRef Medline

Ben-Hur T (2010) Reconstructing neural circuits using transplanted neural stem cells in the injured spinal cord. J Clin Invest 120:3096-3098. CrossRef Medline

Blesch A, Tuszynski MH (2009) Spinal cord injury: plasticity, regeneration and the challenge of translational drug development. Trends Neurosci 32:41-47. CrossRef Medline

Boulenguez P, Vinay L (2009) Strategies to restore motor functions after spinal cord injury. Curr Opin Neurobiol 19:587-600. CrossRef Medline

Boyce VS, Tumolo M, Fischer I, Murray M, Lemay MA (2007) Neurotrophic factors promote and enhance locomotor recovery in untrained spinalized cats. J Neurophysiol 98:1988-1996. CrossRef Medline

Camiletti-Moirón D, Aparicio VA, Aranda P, Radak Z (2013) Does exercise reduce brain oxidative stress? A systematic review. Scand J Med Sci Sports 23:e202-212. CrossRef Medline

Carro E, Nuñez A, Busiguina S, Torres-Alemán I (2000) Circulating insulinlike growth factor I mediates effects of exercise on the brain. J Neurosci 20:2926-2933. Medline

Cheng A, Chan SL, Milhavet O, Wang S, Mattson MP (2001) p38 MAP kinase mediates nitric oxide-induced apoptosis of neural progenitor cells. J Biol Chem 276:43320-43327. CrossRef Medline

Côté MP, Azzam GA, Lemay MA, Zhukareva V, Houlé JD (2011) Activitydependent increase in neurotrophic factors is associated with an enhanced modulation of spinal reflexes after spinal cord injury. J Neurotrauma 28:299-309. CrossRef Medline

Courtine G, Gerasimenko Y, van den Brand R, Yew A, Musienko P, Zhong H, Song B, Ao Y, Ichiyama RM, Lavrov I, Roy RR, Sofroniew MV, Edgerton VR (2009) Transformation of nonfunctional spinal circuits into functional states after the loss of brain input. Nat Neurosci 12:1333-1342. CrossRef Medline

Cusimano M, Biziato D, Brambilla E, Donegà M, Alfaro-Cervello C, Snider S, Salani G, Pucci F, Comi G, Garcia-Verdugo JM, De Palma M, Martino G, Pluchino S (2012) Transplanted neural stem/precursor cells instruct phagocytes and reduce secondary tissue damage in the injured spinal cord. Brain 135:447-460. CrossRef Medline

Dobkin BH, Havton LA (2004) Basic advances and new avenues in therapy of spinal cord injury. Annu Rev Med 55:255-282. CrossRef Medline

Edgerton VR, Roy RR (2012) A new age for rehabilitation. Eur J Phys Rehabil Med 48:99-109. Medline

Edgerton VR, Tillakaratne NJ, Bigbee AJ, de Leon RD, Roy RR (2004) Plasticity of the spinal neural circuitry after injury. Annu Rev Neurosci 27: 145-167. CrossRef Medline

Enoki C, Otani H, Sato D, Okada T, Hattori R, Imamura H (2010) Enhanced mesenchymal cell engraftment by IGF-1 improves left ventricular function in rats undergoing myocardial infarction. Int J Cardiol 138:9 18. CrossRef Medline

Fehlings MG, Vawda R (2011) Cellular treatments for spinal cord injury: the time is right for clinical trials. Neurotherapeutics 8:704-720. CrossRef Medline

Fernandez AM, Torres-Alemán I (2012) The many faces of insulin-like peptide signalling in the brain. Nat Rev Neurosci 13:225-239. CrossRef Medline 
Flynn JR, Dunn LR, Galea MP, Callister R, Callister RJ, Rank MM (2013) Exercise training after spinal cord injury selectively alters synaptic properties in neurons in adult mouse spinal cord. J Neurotrauma 30:891-896. CrossRef Medline

Goldshmit Y, Lythgo N, Galea MP, Turnley AM (2008) Treadmill training after spinal cord hemisection in mice promotes axonal sprouting and synapse formation and improves motor recovery. J Neurotrauma 25: 449-465. CrossRef Medline

Gómez-Pinilla F, Ying Z, Opazo P, Roy RR, Edgerton VR (2001) Differential regulation by exercise of BDNF and NT-3 in rat spinal cord and skeletal muscle. Eur J Neurosci 13:1078-1084. CrossRef Medline

Harkema S, Gerasimenko Y, Hodes J, Burdick J, Angeli C, Chen Y, Ferreira C, Willhite A, Rejc E, Grossman RG, Edgerton VR (2011) Effect of epidural stimulation of the lumbosacral spinal cord on voluntary movement, standing, and assisted stepping after motor complete paraplegia: a case study. Lancet 377:1938-1947. CrossRef Medline

Impey S, Obrietan K, Storm DR (1999) Making new connections: role of ERK/MAP kinase signaling in neuronal plasticity. Neuron 23:11-14. CrossRef Medline

Johanson C, Stopa E, Baird A, Sharma H (2011) Traumatic brain injury and recovery mechanisms: peptide modulation of periventricular neurogenic regions by the choroid plexus-CSF nexus. J Neural Transm 118:115-133. CrossRef Medline

Karimi-Abdolrezaee S, Eftekharpour E (2012) Stem cells and spinal cord injury repair. Adv Exp Med Biol 760:53-73. Medline

Karimi-Abdolrezaee S, Eftekharpour E, Wang J, Morshead CM, Fehlings MG (2006) Delayed transplantation of adult neural precursor cells promotes remyelination and functional neurological recovery after spinal cord injury. J Neurosci 26:3377-3389. CrossRef Medline

Kim BG, Hwang DH, Lee SI, Kim EJ, Kim SU (2007) Stem cell-based cell therapy for spinal cord injury. Cell Transplant 16:355-364. Medline

Kim HM, Hwang DH, Choi JY, Park CH, Suh-Kim H, Kim SU, Kim BG (2011) Differential and cooperative actions of Olig1 and Olig2 transcription factors on immature proliferating cells after contusive spinal cord injury. Glia 59:1094-1106. CrossRef Medline

Kubota K, Saiwai H, Kumamaru H, Maeda T, Ohkawa Y, Aratani Y, Nagano T, Iwamoto Y, Okada S (2012) Myeloperoxidase exacerbates secondary injury by generating highly reactive oxygen species and mediating neutrophil recruitment in experimental spinal cord injury. Spine 37:13631369. CrossRef Medline

Li J, Lepski G (2013) Cell transplantation for spinal cord injury: a systematic review. Biomed Res Int 2013:786475. CrossRef Medline

Li Y, Shelat H, Geng YJ (2012) IGF-1 prevents oxidative stress inducedapoptosis in induced pluripotent stem cells which is mediated by microRNA-1. Biochem Biophys Res Commun 426:615-619. CrossRef Medline

Liu D, Ling X, Wen J, Liu J (2000) The role of reactive nitrogen species in secondary spinal cord injury: formation of nitric oxide, peroxynitrite, and nitrated protein. J Neurochem 75:2144-2154. CrossRef Medline

Llorens-Martin M, Torres-Alemán I, Trejo JL (2010) Exercise modulates insulin-like growth factor 1-dependent and -independent effects on adult hippocampal neurogenesis and behaviour. Mol Cell Neurosci 44:109117. CrossRef Medline

Lu P, Jones LL, Snyder EY, Tuszynski MH (2003) Neural stem cells constitutively secrete neurotrophic factors and promote extensive host axonal growth after spinal cord injury. Exp Neurol 181:115-129. CrossRef Medline

Lu P, Wang Y, Graham L, McHale K, Gao M, Wu D, Brock J, Blesch A, Rosenzweig ES, Havton LA, Zheng B, Conner JM, Marsala M, Tuszynski MH (2012) Long-distance growth and connectivity of neural stem cells after severe spinal cord injury. Cell 150:1264-1273. CrossRef Medline

Lunn JS, Pacut C, Backus C, Hong Y, Johe K, Hefferan M, Marsala M, Feldman EL (2010) The pleotrophic effects of insulin-like growth factor-I on human spinal cord neural progenitor cells. Stem Cells Dev 19:1983-1993. CrossRef Medline

Nakamura M, Okano H (2013) Cell transplantation therapies for spinal cord injury focusing on induced pluripotent stem cells. Cell Res 23:70-80. CrossRef Medline

Oh MJ, Seo TB, Kwon KB, Yoon SJ, Elzi DJ, Kim BG, Namgung U (2009)
Axonal outgrowth and Erk1/2 activation by training after spinal cord injury in rats. J Neurotrauma 26:2071-2082. CrossRef Medline

Okada S, Ishii K, Yamane J, Iwanami A, Ikegami T, Katoh H, Iwamoto Y, Nakamura M, Miyoshi H, Okano HJ, Contag CH, Toyama Y, Okano H (2005) In vivo imaging of engrafted neural stem cells: its application in evaluating the optimal timing of transplantation for spinal cord injury. FASEB J 19:1839-1841. CrossRef Medline

Petruska JC, Ichiyama RM, Jindrich DL, Crown ED, Tansey KE, Roy RR, Edgerton VR, Mendell LM (2007) Changes in motoneuron properties and synaptic inputs related to step training after spinal cord transection in rats. J Neurosci 27:4460-4471. CrossRef Medline

Radak Z, Chung HY, Goto S (2008a) Systemic adaptation to oxidative challenge induced by regular exercise. Free Radic Biol Med 44:153-159. CrossRef Medline

Radak Z, Chung HY, Koltai E, Taylor AW, Goto S (2008b) Exercise, oxidative stress and hormesis. Ageing Res Rev 7:34-42. CrossRef Medline

Rossignol S, Schwab M, Schwartz M, Fehlings MG (2007) Spinal cord injury: time to move? J Neurosci 27:11782-11792. CrossRef Medline

Roy RR, Harkema SJ, Edgerton VR (2012) Basic concepts of activity-based interventions for improved recovery of motor function after spinal cord injury. Arch Phys Med Rehabil 93:1487-1497. CrossRef Medline

Ruff CA, Wilcox JT, Fehlings MG (2012) Cell-based transplantation strategies to promote plasticity following spinal cord injury. Exp Neurol 235: 78-90. CrossRef Medline

Sahni V, Kessler JA (2010) Stem cell therapies for spinal cord injury. Nat Rev Neurol 6:363-372. CrossRef Medline

Sakata H, Niizuma K, Wakai T, Narasimhan P, Maier CM, Chan PH (2012) Neural stem cells genetically modified to overexpress cu/zn-superoxide dismutase enhance amelioration of ischemic stroke in mice. Stroke 43 : 2423-2429. CrossRef Medline

Speck AE, Tromm CB, Pozzi BG, Paganini CS, Tuon T, Silveira PC, Aguiar AS Jr, Pinho RA (2014) The Dose-Dependent Antioxidant Effects of Physical Exercise in the Hippocampus of Mice. Neurochem Res.

Stranahan AM, Lee K, Becker KG, Zhang Y, Maudsley S, Martin B, Cutler RG, Mattson MP (2010) Hippocampal gene expression patterns underlying the enhancement of memory by running in aged mice. Neurobiol Aging 31:1937-1949. CrossRef Medline

Teng YD, Liao WL, Choi H, Konya D, Sabharwal S, Langer R, Sidman RL, Snyder EY, Frontera WR (2006) Physical activity-mediated functional recovery after spinal cord injury: potential roles of neural stem cells. Regen Med 1:763-776. CrossRef Medline

Tseng BP, Giedzinski E, Izadi A, Suarez T, Lan ML, Tran KK, Acharya MM Nelson GA, Raber J, Parihar VK, Limoli CL (2014) Functional consequences of radiation-induced oxidative stress in cultured neural stem cells and the brain exposed to charged particle irradiation. Antioxid Redox Signal 20:1410-1422. CrossRef Medline

Varma AK, Das A, Wallace G 4th, Barry J, Vertegel AA, Ray SK, Banik NL (2013) Spinal cord injury: a review of current therapy, future treatments, and basic science frontiers. Neurochem Res 38:895-905. CrossRef Medline

Xiong Y, Hall ED (2009) Pharmacological evidence for a role of peroxynitrite in the pathophysiology of spinal cord injury. Exp Neurol 216:105114. CrossRef Medline

Yaksh TL, Rudy TA (1976) Chronic catheterization of the spinal subarachnoid space. Physiol Behav 17:1031-1036. CrossRef Medline

Yasuda A, Tsuji O, Shibata S, Nori S, Takano M, Kobayashi Y, Takahashi Y, Fujiyoshi K, Hara CM, Miyawaki A, Okano HJ, Toyama Y, Nakamura M, Okano H (2011) Significance of remyelination by neural stem/progenitor cells transplanted into the injured spinal cord. Stem Cells 29:19831994. CrossRef Medline

Ying Z, Roy RR, Edgerton VR, Gómez-Pinilla F (2005) Exercise restores levels of neurotrophins and synaptic plasticity following spinal cord injury. Exp Neurol 193:411-419. CrossRef Medline

Yoon C, Tuszynski MH (2012) Frontiers of spinal cord and spine repair: experimental approaches for repair of spinal cord injury. Adv Exp Med Biol 760:1-15. Medline

Yu D, Neeley WL, Pritchard CD, Slotkin JR, Woodard EJ, Langer R, Teng YD (2009) Blockade of peroxynitrite-induced neural stem cell death in the acutely injured spinal cord by drug-releasing polymer. Stem Cells 27: 1212-1222. CrossRef Medline 